\title{
Anti-inflammatory properties of a novel peptide interleukin 1 receptor antagonist
}

\author{
Boris Klementiev', Shizhong Li ${ }^{1}$, Irina Korshunova ${ }^{1}$, Oksana Dmytriyeva', Stanislava Pankratova ${ }^{1}$, Peter S Walmod ${ }^{1}$, \\ Laura K Kjær ${ }^{2}$, Mattias S Dahllöf², Morten Lundh², Dan P Christensen², Thomas Mandrup-Poulsen ${ }^{2,3}$, \\ Elisabeth Bock ${ }^{1}$ and Vladimir Berezin ${ }^{1 *}$
}

\begin{abstract}
Background: Interleukin 1 (IL-1) is implicated in neuroinflammation, an essential component of neurodegeneration. We evaluated the potential anti-inflammatory effect of a novel peptide antagonist of IL-1 signaling, Ilantide.

Methods: We investigated the binding of llantide to IL-1 receptor type I (IL-1RI) using surface plasmon resonance, the inhibition of II-1 $\beta$-induced activation of nuclear factor KB (NF-KB) in HEK-Blue cells that contained an IL-1 $\beta$-sensitive reporter, the secretion of TNF- $a$ in macrophages, protection against IL-1-induced apoptosis in neonatal pancreatic islets, and the penetration of llantide through the blood-brain barrier using competitive enzyme-linked immunosorbent assay (ELISA). We studied the effects of the peptide on social behavior and memory in rat models of lipopolysaccharide (LPS)- and amyloid-induced neuroinflammation, respectively, and its effect in a rat model of experimental autoimmune enchephalomyelitis.
\end{abstract}

Results: llantide bound IL-1RI, inhibited the IL-1 $\beta$-induced activation of NF-KB, and inhibited the secretion of TNF-a in vitro. llantide protected pancreatic islets from apoptosis in vitro and reduced inflammation in an animal model of arthritis. The peptide penetrated the blood-brain barrier. It reduced the deficits in social activity and memory in LPS- and amyloid-treated animals and delayed the development of experimental autoimmune enchephalomyelitis.

Conclusions: These findings indicate that llantide is a novel and potent IL-1RI antagonist that is able to reduce inflammatory damage in the central nervous system and pancreatic islets.

Keywords: Amyloid- $\beta$, Antagonistic peptide, Experimental autoimmune encephalitis, Inflammation, Interleukin 1, LPS, Pancreatic islets

\section{Introduction}

Interleukin 1 (IL-1) is a key mediator of the acute-phase inflammatory response and has been implicated as the mediator of tissue dysfunction and destruction in chronic inflammatory diseases such as amyotrophic lateral sclerosis, diabetes and rheumatoid arthritis. IL-1 is also believed to mediate neuroinflammation in neurodegenerative conditions, including Alzheimer's disease (AD) [1]. IL-1 signals via IL-1 receptor type I (IL-1RI), which binds both the IL- $1 \alpha$ and IL-1 $\beta$ isoforms [2]. Once bound to the receptor, the IL-1 receptor accessory

\footnotetext{
* Correspondence: berezin@sund.ku.dk

'Laboratory of Neural Plasticity, Department of Neuroscience and Pharmacology, University of Copenhagen, Blegdamsvej 3, DK-2200 Copenhagen, Denmark

Full list of author information is available at the end of the article
}

protein (IL-1RAcP) is recruited, allowing nuclear factor $\kappa \mathrm{B}(\mathrm{NF}-\kappa \mathrm{B})$ and mitogen-activated protein kinase (MAPK) signaling to trigger the expression and release of a multitude of inflammatory mediators, including chemokines and cytokines. IL-1 antagonists encompass IL-1 receptor antagonist (IL-1Ra), IL-1-neutralizing antibodies and the IL-1 trap, a linear fusion protein between the soluble IL-1 receptor (sIL-RI) and IL-1RAcP. IL-1Ra binds to IL-1RI, but it does not initiate signaling, because it does not engage IL-1RAcP [3,4]. These biologics are indicated for the treatment of autoinflammatory diseases and rheumatoid arthritis and have shown promising results in clinical trials for other inflammatory conditions. Anakinra (Ana) is a recombinantly produced protein that contains the $\mathrm{N}$-terminal, methionylated, nonglycosylated version of human IL-1Ra, which competitively blocks the

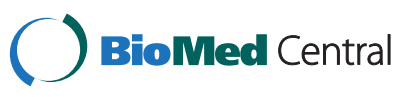


actions of IL-1 without any detectable agonist activity. Ana has been used for the treatment of rheumatoid arthritis, adult-onset Still's disease, systemic onset juvenile idiopathic arthritis, osteoarthritis and type 2 diabetes mellitus $[5,6]$. However, the relatively poor penetration of the blood-brain barrier (BBB) [7] restricts therapeutic use of the current macromolecular IL-1 antagonist proteins for the treatment of neuroinflammation [8].

In the present study, we identified and characterized a novel synthetic peptide, ten amino acids long, termed Ilantide, which is derived from the human IL-Ra $\mathrm{N}$-terminal domain involved in interactions with IL-1RI. We hypothesized that Ilantide would compete with IL-1R signaling, thereby inhibiting inflammatory responses induced by various conditions in vitro and in vivo. Indeed, we found that Ilantide bound to IL-1RI and inhibited the IL-1-induced activation of NF- $\mathrm{kB}$ and secretion of tumor necrosis factor $\alpha$ (TNF- $\alpha$ ) by macrophages. It protected pancreatic islets from IL- $1 \beta$-induced apoptosis and reduced inflammation in collagen-induced arthritis (CIA). The peptide penetrated the BBB, ameliorated decline in social activity and memory in lipopolysaccharide (LPS)- and amyloid-treated animals and delayed the development of experimental autoimmune encephalomyelitis (EAE).

\section{Materials and methods}

\section{Peptides and recombinant proteins}

The Ilantide peptide (SGRKSSKMQA), scrambled peptide1 (KQSAGKRSMS), scrambled peptide2 (KASQKGMSRS) and Ilantide peptide with a reversed sequence (AQMK SSKRGS) were purchased from Schafer-N (Copenhagen, Denmark). The peptides were synthesized using the fluorenylmethyloxycarbonyl protection strategy on TentaGel resin (Rapp Polymere, Tübingen, Germany). The peptides were synthesized as either monomers (Ilantide-m) or dendrimers composed of four monomers coupled to a lysine backbone (Ilantide- $\mathrm{t}$ ) and were further purified by gel filtration using Sephadex G-10 (Amersham Biosciences, Uppsala, Sweden). The peptides were at least $85 \%$ pure according to estimation by high-performance liquid chromatography. The recombinant proteins (that is, IL-1 $\beta, \mathrm{IL}-6$, TNF- $\alpha$, interferon $\gamma$ (IFN- $\gamma$ ), IL-1Ra and the ectodomain of IL-1RI) were purchased from R\&D Systems (Minneapolis, MN, USA). Ana (Kineret) was obtained from Amgen (Thousand Oaks, CA, USA).

\section{Surface plasmon resonance analysis}

The binding analysis was performed using a Biacore 2000 instrument (GE Healthcare Life Sciences) that contained $150 \mathrm{mM} \mathrm{NaCl}$ as running buffer at $25^{\circ} \mathrm{C}$ with $10 \mathrm{mM}$ sodium phosphate ( $\mathrm{pH}$ 7.4). The flow rate was 5 $\mu \mathrm{l} / \mathrm{min}$ during immobilization. Ilantide peptide, IL- $1 \beta$ or IL-1Ra was immobilized on a CM4 sensor chip according to the manufacturer's instructions, after which the recombinant ectodomain of IL-1RI (R\&D Systems) was injected. The neural cell adhesion molecule (NCAM) immunoglobulin modules 1 and 2 (Ig1 and Ig2) were used as a negative control protein [9]. The data were analyzed using nonlinear curve-fitting with the manufacturer's software.

\section{Cell cultures}

HEK-Blue IL- $1 \beta$ cells that contained an IL- $1 \beta$-sensitive reporter (InvivoGen, San Diego, CA, USA) and HEK-Blue IL-6 cells that contained an IL-6-sensitive reporter (InvivoGen) were grown at $37^{\circ} \mathrm{C}$ with $5 \% \mathrm{CO}_{2}$ in Dulbecco's modified Eagle's medium (DMEM) supplemented with 5\% (vol/vol) fetal calf serum (FCS), $4.5 \mathrm{~g} / \mathrm{L}$ glucose, $2 \mathrm{mM}$ GlutaMAX medium, $100 \mathrm{U} / \mathrm{ml}$ penicillin, $100 \mu \mathrm{g} / \mathrm{ml}$ streptomycin (all obtained from Gibco BRL/Life Technologies, Taastrup, Denmark), $100 \mu \mathrm{g} / \mathrm{ml}$ zeocin, 200 $\mu \mathrm{g} / \mathrm{ml}$ hygromycin and $100 \mu \mathrm{g} / \mathrm{ml}$ Normocin (all purchased from InvivoGen).

A murine alveolar macrophage cell line, AMJ2-C8 (American Type Culture Collection, Borås, Sweden), was routinely grown at $37^{\circ} \mathrm{C}$ with $5 \% \mathrm{CO}_{2}$ in DMEM supplemented with $5 \%$ (vol/vol) FCS, 0.5\% (v/v) 2-[4-(2-hydroxyethyl)piperazin-1-yl]ethanesulfonic acid (HEPES) (Gibco BRL), $2 \mathrm{mM}$ GlutaMAX, $100 \mathrm{U} / \mathrm{ml}$ penicillin and $100 \mu \mathrm{g} /$ $\mathrm{ml}$ streptomycin.

Cerebellar granule neurons (CGNs) were prepared from 7-day-old Wistar rats (from Charles River Laboratories, Sulzfeld, Germany; or from Hygind Møllegård Erik Møllegaard Hansen, Ejby, Denmark) as previously described [10]. Briefly, the cerebella were cleared of meninges and blood vessels, roughly homogenized by chopping and trypsinized. The cells were washed in the presence of DNAse I and soybean trypsin inhibitor (Sigma-Aldrich, St Louis, MO, USA), and cellular debris was pelleted by centrifugation. The fibroblastoid mouse cell line L929 (LVN; European Collection of Cell Cultures, Porton Down, UK) was routinely grown at $37^{\circ} \mathrm{C}$ with 5\% $\mathrm{CO}_{2}$ in DMEM supplemented with $10 \%$ (vol/ vol) FCS, $2 \mathrm{mM}$ GlutaMAX, $100 \mathrm{U} / \mathrm{ml}$ penicillin and $100 \mu \mathrm{g} / \mathrm{ml}$ streptomycin.

\section{Rat islet isolation and culture}

Neonatal rat islets were isolated from 3- to 6-day-old outbred Wistar rats (Taconic, Ejby, Denmark) as previously described [11]. Islets were precultured and maintained in RPMI 1640 medium (Gibco/Life Technologies) supplemented with $20 \mathrm{mmol} / \mathrm{L}$ HEPES buffer, $0.038 \%$ (wt/vol) $\mathrm{NaHCO}_{3}, 100 \mathrm{U} / \mathrm{ml}$ penicillin, $100 \mathrm{~g} / \mathrm{ml}$ streptomycin and $10 \%$ (vol/vol) newborn calf serum (NCS) at $37^{\circ} \mathrm{C}$ in humidified atmospheric air. Prior to experimentation, the islets were randomly distributed to 24-well dishes and incubated for 2 hours in RPMI 1640 medium 
supplemented as described above, but with $0.5 \%$ ( $\mathrm{vol} / \mathrm{vol})$ NCS relevant reagents were added as indicated.

\section{Nuclear factor $\mathbf{\kappa B}$ activation}

HEK-Blue IL-1 $\beta$ cells allow the monitoring of the activation of the NF- $\mathrm{kB}$ pathway specifically in response to IL-1 $\beta$. They express a NF- $\kappa B$-inducible secreted embryonic alkaline phosphatase (SEAP) reporter gene. The binding of IL-1 $\beta$ to its receptor IL-1RI on the surface of HEK-Blue IL-1 $\beta$ cells triggers a signaling cascade that leads to the activation NF- $\mathrm{kB}$ and the subsequent production of SEAP. HEK-Blue IL-1 $\beta$ cells were grown as described above. The cells were seeded onto a 96-well plate at a density $3.5 \times 10^{5}$ cells $/ \mathrm{ml}$. For the NF- $\mathrm{kB}$ activation assay, the cells were treated with $1.2 \mathrm{pM} \mathrm{IL-1} \beta$ alone or together with sIL-1RI, IL-1Ra or various concentrations of Ilantide. After 24 hours of incubation at $37^{\circ} \mathrm{C}, 150 \mu \mathrm{l}$ of the cell supernatants were added to each well of a 96-well plate together with $50 \mu \mathrm{l}$ of QUANTIBlue (InvivoGen), incubated at $37^{\circ} \mathrm{C}$ for 40 minutes and measured in an enzyme-linked immunosorbent assay (ELISA) reader at $600 \mathrm{~nm}$ to determine the expression levels of reporter genes activated by NF- $\mathrm{kB}$.

\section{Signal transducer and activator of transcription 3 activation}

HEK-Blue IL-6 cells were grown as described above. IL-6 cells allow the monitoring of the activation of the signal transducer and activator of transcription 3 (STAT3) pathway specifically in response to IL-6. They express a STAT3-inducible SEAP reporter gene. For the STAT3 activation assay, the cells were treated with 1.2 pM IL- 6 alone or together with various concentrations of Ilantide. TNF- $\alpha$ (1.2 pM) was added as a control ligand for both the NF-kB and STAT3 assays. After 24-hour incubation at $37^{\circ} \mathrm{C}, 150$ $\mu \mathrm{l}$ of HEK-Blue cell supernatant were added to each well of a 96-well plate together with $50 \mu \mathrm{l}$ of QUANTI-Blue (InvivoGen), incubated at $37^{\circ} \mathrm{C}$ in the dark for 40 minutes and measured in an ELISA reader at $600 \mathrm{~nm}$ to determine the expression level of the secreted SEAP.

\section{Tumor necrosis factor a secretion}

AMJ2-C8 macrophages were seeded into six-well multidishes at a density of $2.5 \times 10^{5}$ cells/well, and sIL-1RI, IL-1Ra or various concentrations of Ilantide were added to the cultures. Treatment with $100 \mu \mathrm{M}$ hydrocortisone (Sigma-Aldrich, Brøndby, Denmark) was used as a positive control. After 10 -minute incubation at $37^{\circ} \mathrm{C}, 1.2 \mathrm{pM}$ IL- $1 \beta$ or IFN- $\gamma$ (R\&D Systems) was added to activate the macrophages. L929 cells were seeded onto a 96-well plate (Nunc, Roskilde, Denmark) at a density $0.2 \times 10^{2}$ cells $/ \mathrm{ml}$. Both cell cultures were incubated for 24 hours at $37^{\circ} \mathrm{C}$. Conditioned medium from macrophages was collected and added to the L929 cell cultures together with actinomycin D (0.6 $\mu \mathrm{g} /$ well; Sigma-Aldrich). TNF- $\alpha$ is known to induce classic apoptosis in L929 cells in the presence of actinomycin D [12]. After 24-hour incubation at $37^{\circ} \mathrm{C}, 20 \mu \mathrm{l}$ of 3-(4,5-dimethylthiazol-2-yl)5-(3-carboxymethoxyphenyl)-2-(4-sulfophenyl)- $2 H$-tetrazolium (Promega, Madison, WI, USA) were added to each well and incubated at $37^{\circ} \mathrm{C}$ in the dark for $45 \mathrm{mi}$ nutes, then measured in an ELISA reader at $490 \mathrm{~nm}$. To calculate the amount of TNF- $\alpha$ in the conditioned medium, fibroblasts were treated with standard concentrations of TNF- $\alpha$ (R\&D Systems).

\section{Cell survival and apoptosis}

\section{Pancreatic islets and nitric oxide production}

For cell death detection, rat islets were incubated with 150 pg/ml IL-1 $\beta$ (BD Pharmingen, San Diego, CA, USA) alone or in combination with various concentrations of Ana and Ilantide for 24 hours at $37^{\circ} \mathrm{C}$ in humidified atmospheric air. Rat islet cell death was assessed by cell death detection ELISA (Roche, Lund, Sweden) as previously described [13]. As a surrogate measure of nitric oxide production, Griess reagent (1:1 aqueous mixture of $0.1 \%$ naphthylethylenediamine hydrochloride and $1 \%$ sulfanilamide $+5 \% \mathrm{H}_{3} \mathrm{PO}_{4}$ ) was mixed in a $1: 1$ ratio with $100 \mu \mathrm{l}$ of supernatant samples to determine the nitrite content in supernatants from the cell death assays described above.

\section{Primary neurons}

Cerebellar granule neurons were plated at a density of $1 \times 10^{5}$ cells $/ \mathrm{cm}^{2}$ on poly-L-lysine-coated, eight-well Permanox Lab-Tek chamber slides (Nunc) in Neurobasal-A medium supplemented with $2 \%$ (vol/vol) B27 (Gibco BRL), $0.5 \%$ (vol/vol) GlutaMAX, $100 \mathrm{U} / \mathrm{ml}$ penicillin and $100 \mu \mathrm{g} / \mathrm{ml}$ streptomycin. The CGN survival assay was performed as previously described [14]. The neurite outgrowth assay was also performed as previously described [15].

\section{Animal studies}

Male Wistar rats (Charles River Laboratories) weighing 150 to $200 \mathrm{~g}$ on the day of arrival in the laboratory were housed two per cage. Juvenile rats (3 weeks old, weight 40 to $50 \mathrm{~g}$ ) were housed in groups of three. All of the animals were kept under standard conditions $\left(23^{\circ} \mathrm{C}, 50 \%\right.$ humidity, 12:12-hour light-dark cycle) with free access to food and water. All of the experiments were performed according to European Union legislation with licenses from the Danish Animal Experiments Inspectorate (2008/561-1539, 2008/561-1524 and 2009/561-1686). The number of animals utilized in the respective experimental groups was kept to a minimum, and all of the work was conducted in a manner designed to cause the least harm and suffering to the animals. 


\section{Pharmacokinetics}

Biotinylated Ilantide-t (Schafer-N) was administered to adult male Wistar rats subcutaneously (s.c.) at a dose of $10 \mathrm{mg} / \mathrm{kg}$. Twenty minutes, sixty minutes, one hundred forty minutes, five hours and thirty hours after peptide administration, blood samples (approximately 300 $\mu \mathrm{l})$ were collected from the orbital plexus under fentanyl/droperidol/midazolam anesthesia (0.002\%/0.14\%/ $0.014 \% \mathrm{wt} / \mathrm{vol}$ ) (Department of Experimental Medicine, University of Copenhagen, Denmark) in ethylenediaminetetraacetic acid-coated tubes (BD, Plymouth, UK), and 50 to $110 \mathrm{U} / \mathrm{ml}$ aprotinin (Calbiochem, San Diego, CA, USA) was added immediately to the collected blood. The samples were subsequently centrifuged at $1,500 \times g$ for 15 minutes. Cerebrospinal fluid (CSF) was collected from the cisterna magna 30 minutes after peptide administration as described previously [16]. Plasma and CSF samples were stored at $-80^{\circ} \mathrm{C}$.

The concentrations of Ilantide-t in plasma and CSF samples were measured by performing a competitive ELISA on amino 96-well plates (Nunc). The bottoms of the wells were coated with biotinylated bovine serum albumin (Sigma-Aldrich) diluted in coating buffer (0.1 M Na-carbonate buffer, $\mathrm{pH}$ 9.6) to a concentration of $1 \mu \mathrm{g} / \mathrm{ml}$, and $100 \mu \mathrm{l}$ were applied to each well. The plates were incubated overnight at $4^{\circ} \mathrm{C}$ and then washed three times in washing buffer (PBS with $0.1 \% \mathrm{vol} / \mathrm{vol}$ Tween 20, pH 7.4). One volume of diluted sample or a standard with a known concentration of the biotin-labeled Ilantide was pipetted into the wells of a mixing Protein LoBind Eppendorf Plate (Eppendorf, Hamburg, Germany) and incubated with three volumes of streptavidin-peroxidase (Dako Denmark A/S, Glostrup, Denmark) diluted $1: 10,000$ in washing buffer. After preincubation for 30 minutes, $100 \mu \mathrm{l}$ of the resulting incubation mixture were transferred onto the prepared ELISA plate and then incubated for 1 hour at $37^{\circ} \mathrm{C}$. The plate was then washed three times in washing buffer, and 3,3',5,5' -tetramethylbenzidine substrate (Kem-En-Tec Diagnostics, Taastrup, Denmark) was added (100 $\mu \mathrm{l} /$ well $)$ for 5 to 10 minutes at room temperature. Color development was terminated by the addition of $2 \mathrm{M} \mathrm{H}_{2} \mathrm{SO}_{4}$ (100 $\mu \mathrm{l} /$ well), and absorbance was read at $450 \mathrm{~nm}$ on a Wallac Victor 1420 multilabel counter (PerkinElmer, Hvidovre, Denmark). Peptide concentrations in the samples were determined using a standard curve. Samples from four to six animals were used for each time point and run in duplicate. Two independent determinations were performed.

\section{Collagen-induced arthritis in rats}

CIA was induced by bovine collagen type II (CII; SigmaAldrich) solubilized in $0.05 \mathrm{M}$ acetic acid $(2 \mathrm{mg} / \mathrm{ml})$, then emulsified 1:1 with complete Freund's adjuvant (CFA) (Sigma-Aldrich) that contained $1.0 \mathrm{mg} / \mathrm{ml}$ heat- inactivated Mycobacterium tuberculosis. While the animals were under inhalation anesthesia (3\% isoflurane; Baxter, Allerød, Denmark), $250 \mu$ of the emulsion that contained $250 \mu \mathrm{g}$ of $\mathrm{CII}$ and $125 \mu \mathrm{g}$ of $M$. tuberculosis were injected intradermally at the tail base (day postimmunization 0 (dpi 0)). On dpi 8, before the onset of clinical signs, all of the animals were randomly divided into two groups, with 20 rats per group, and dosed daily for 8 days (dpi 8 to 15$)$ with Ilantide s.c. $(10 \mathrm{mg} / \mathrm{kg})$ or vehicle s.c. (1.0 ml/kg PBS). Clinical evaluations were performed on dpi 7 to 16. An observer who was blinded to the treatment groups evaluated the severity of arthritis by employing the following grading system: 0 (no redness or swelling of the foot), 1 (slight redness in the foot or redness and swelling in single interphalangeal joints), 2 (moderate swelling and redness in the ankle and metatarsal part of the foot), 3 (marked swelling and redness of the entire foot, with restricted use of the foot during locomotion) and 4 (marked swelling and redness of the entire foot, with no use of the foot during locomotion). CIA typically involves only the hindlimbs, and the arthritic index was defined as the sum of the two limb scores. The animals were killed when the severity of arthritis reached a score of 7 . The differences in the area under the clinical score curve during the period of observation between the control and peptide-treated groups were calculated, with baseline defined as the start of treatment (that is, 0 ).

\section{Lipopolysaccharide-induced impairment of social behavior}

The peripheral administration of LPS, the active fragment of bacterial endotoxin, results in an increase in the plasma levels of all proinflammatory cytokines and behavioral depression [8]. LPS-induced behavioral depression was assessed by measuring the reduction of the duration of social interaction during 4-minute sessions. Six- to seven-week-old rats were handled for five days, habituated to the test cages and the experiment room and trained for social interaction with three-week-old juvenile rats introduced into the test cage for four minutes two days before the actual experiment. On the day of the experiment, the rats were intraperitoneally injected (i.p.) with saline or LPS (Escherichia coli 0111:B4; Sigma-Aldrich) dissolved in saline $(250 \mu \mathrm{g} / \mathrm{kg})$. Immediately after the i.p. injection, Ilantide-t (Ila; $10 \mathrm{mg} / \mathrm{kg}$, equivalent to $2.1 \mu \mathrm{mol} / \mathrm{kg})$, Ana $(100 \mathrm{mg} / \mathrm{kg}$, equivalent to $5.8 \mu \mathrm{mol} / \mathrm{kg}$ ) or saline was injected subcutaneously. The volume of all of the injections was $1.0 \mathrm{ml} / \mathrm{kg}$. Six experimental groups were used: vehicle i.p./vehicle s.c. (veh/veh; $n=10$ ), vehicle i.p./Ilantide-t s.c. (veh/Ila; $n=8$ ), vehicle i.p./Ana s.c. (veh/Ana; $n=9$ ), LPS i.p./vehicle s.c. (LPS/veh; $n=10$ ), LPS i.p./Ilantide-t s.c. (LPS/ Ila; $n=11$ ) and LPS i.p./Ana s.c. (LPS/Ana; $n=11$ ). The injections and weighing of the rats were performed 
immediately after the first test session $(0 \mathrm{~h})$, and the animals were tested and weighed again 2, 4, 6, 8, and 24 hours later. Different juvenile animals were presented on each occasion. Social interaction consisted of anogenital sniffing, licking and chewing the fur of the juveniles by the experimental animals and was monitored with a video camera. Animals that showed less than 40 seconds of investigation of the juveniles during the baseline session were excluded. The duration of social interaction at each time point is expressed as the percentage of baseline values and was averaged for each experimental group. Social interaction was scored by an observer who was blinded to the treatment of the animals. For evaluation of levels of pro- and antiinflammatory cytokines in blood, rats were injected with LPS and then immediately with either vehicle $(n=8)$ or Ilantide-t $(n=8)$ as described above. In addition, a control group of animals $(n=4)$ was treated with Ilantide-t alone (control). Blood samples were collected at 0, 2 and 6 hours after injections as described for the pharmacokinetics study and stored at $-20^{\circ} \mathrm{C}$ until use. The levels of IL-6, IFN- $\gamma$ and IL-10 were determined using corresponding rat ELISA kits according to the manufacturer's protocols (all from BD Biosciences, San Diego, CA, USA).

\section{Intracerebroventricular administration of the $A \beta_{25-35}$ peptide}

Aggregates of $A \beta_{25-35}$ (Bachem AG, Weil am Rhein, Germany) were prepared by incubating the peptides at a concentration of $3 \mu \mathrm{g} / \mu \mathrm{l}$ in sterile water for 4 days at $37^{\circ} \mathrm{C}$. Subsequently, $5 \mu \mathrm{l}$ of aggregated $\mathrm{A} \beta_{25-35}$ were injected intracerebroventricularly $(1.2 \mu \mathrm{l} / \mathrm{min})$ with a $10-\mu \mathrm{l}$ Hamilton syringe using the following coordinates: $0.8 \mathrm{~mm}$ posterior to the bregma, $1.5 \mathrm{~mm}$ lateral to the sagittal suture and $3.8 \mathrm{~mm}$ beneath the surface of the brain. The procedure was performed while the animals were under anesthesia (i.p. fentanyl-fluanisone/midazolam at $0.3 \mathrm{ml} /$ $100-\mathrm{g}$ animal; that is, $23.6 \mu \mathrm{g}$ of fentanyl, $0.75 \mathrm{mg}$ of fluanisone and $375 \mu \mathrm{g}$ midazolam per 100-g animal).

\section{Social recognition test}

Social memory in animals reflects the ability of individuals to recognize conspecifics as familiar or unfamiliar. The social recognition test is a measure of short-term memory and is suitable for studies of AD-like dementia because it evaluates the function of neural structures that involve the cholinergic system, which is impaired in $\operatorname{AD}[17,18]$. The animals were handled for 5 days, habituated to the test cage and trained to interact with a juvenile rat. Three groups of rats were used: a control group of untreated rats $(n=11)$, an amyloid-/vehicle-treated group $(n=13)$ and an amyloid/Ilantide-t-treated group $(n=12)$. Aggregated amyloid- $\beta$ protein fragment 25 to $35\left(\mathrm{~A} \beta_{25-35} ; 15 \mu \mathrm{g}\right)$ was injected into the lateral ventricle. Ilantide-t $(10 \mathrm{mg} / \mathrm{kg})$ or vehicle $(1 \mathrm{ml} / \mathrm{kg}$ saline) was injected subcutaneously on days $7,9,11,13,15,17$ and 19 after $A \beta$ administration. The social recognition test was conducted on day 20. Every rat was tested three times. The first and second trials $\left(\mathrm{T}_{1}\right.$ and $\mathrm{T}_{2}$ ) were performed with the same juvenile. In the third trial $\left(\mathrm{T}_{3}\right)$, the rats were tested with a new juvenile. The trial lasted 4 minutes with a 30-minute intertrial interval. During each trial, the investigative behavior of the adult toward the juvenile (that is, licking, sniffing and chewing the fur of the juvenile) was monitored with a video camera and scored by an observer who was blinded to the treatment of the animals. Animals that showed less than $40 \mathrm{sec}-$ onds of investigation of the juvenile during the initial trial

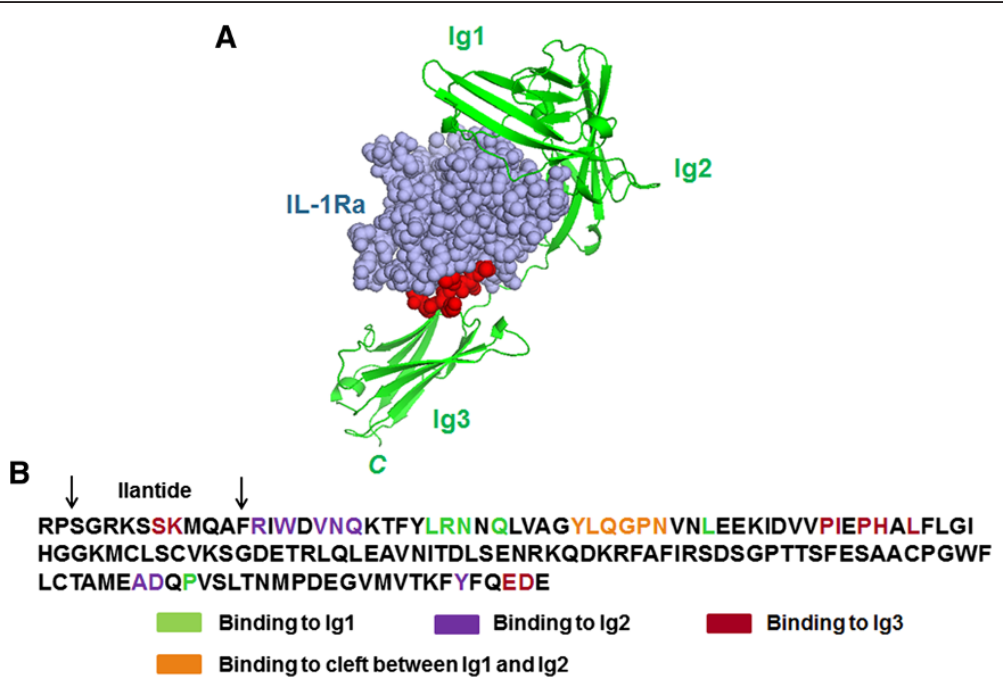

Figure 1 Design of the peptide llantide. (A) Tertiary structure model of the complex between interleukin 1 receptor antagonist (IL-1Ra) (space filled with purple) and IL-1 receptor type I (IL-1RI) (backbone and secondary structures in green). The location of the llantide peptide sequence is shown in red. (B) The IL-1Ra sequence with the mapped IL-1RI binding site and Ilantide motif is shown. 


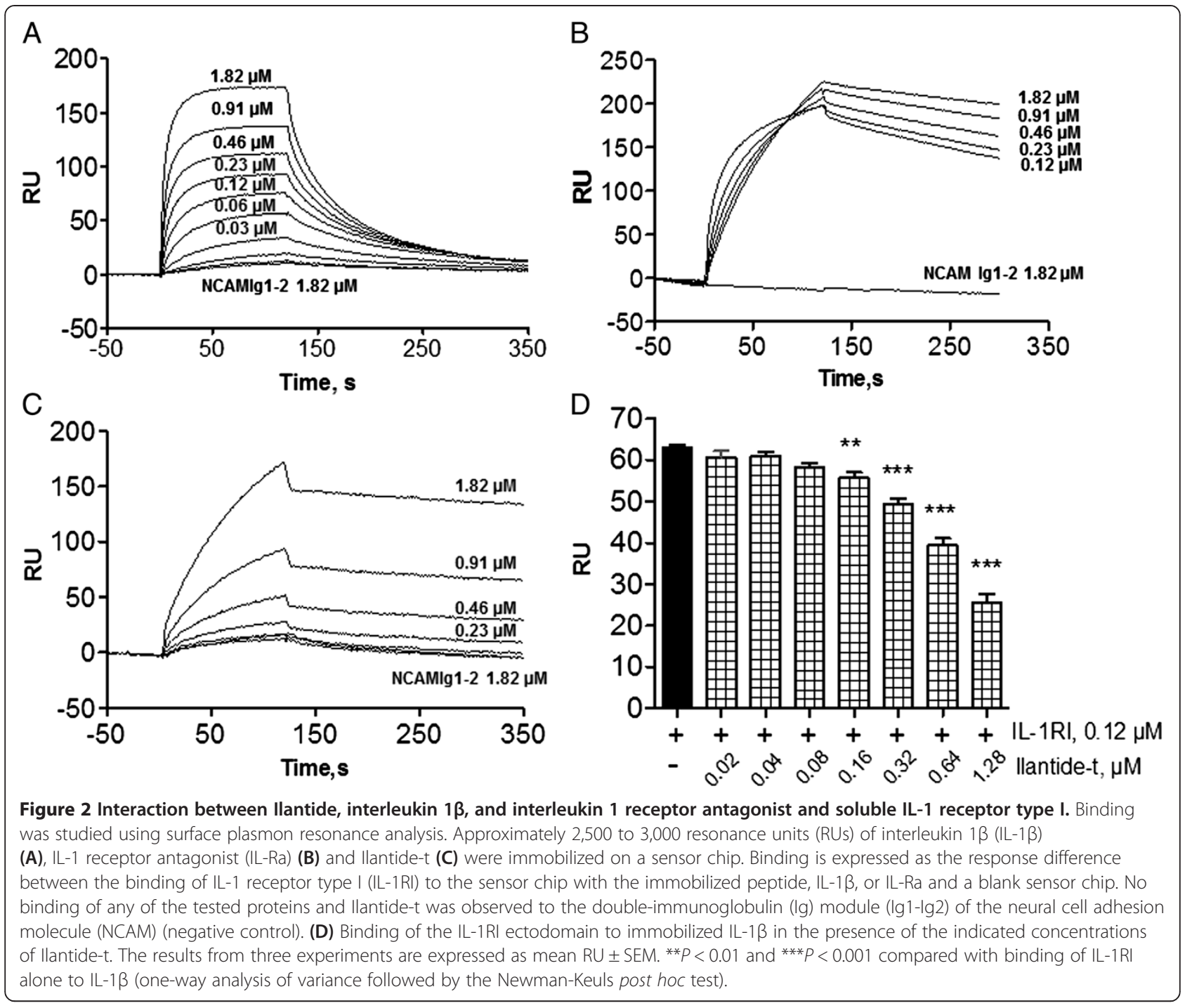

were excluded. Social memory was estimated as a recognition ratio (RR). $R R_{\text {familiar }}$ was calculated as $T_{2} /\left(T_{1}+T_{2}\right) . T_{1}$ and $T_{2}$ are the time spent investigating the juvenile animal during the first and second trials. The time spent investigating a novel juvenile $\left(\mathrm{T}_{3}\right)$ was measured to confirm that the effect seen with the familiar juvenile was specific to cognition. In this case, $\mathrm{RR}_{\text {new }}$ was calculated as $\mathrm{T}_{3} /\left(\mathrm{T}_{1}+\right.$ $\mathrm{T}_{3}$ ). An $\mathrm{RR}$ value significantly less than the theoretical value of 0.5 , calculated by a one-sample $t$-test, was taken as an indication of the presence of social memory.

\section{Experimental autoimmune encephalomyelitis}

Experimental autoimmune enchephalomyelitis was induced in female Lewis rats by guinea pig myelin basic protein (MBP) emulsified with CFA (Sigma-Aldrich) that contained $1.0 \mathrm{mg} / \mathrm{ml}$ heat-inactivated M. tuberculosis. While the animals were under inhalation anesthesia (3\% isoflurane; Baxter), $200 \mu \mathrm{l}$ of an emulsion that contained
$200 \mu \mathrm{g}$ of MBP were subcutaneously injected at the tail base (dpi 0). Between dpi 0 and 21, weight and clinical signs of EAE were recorded daily for all of the animals. Clinical signs were scored as follows: 0 (no abnormality), 0.5 (weak tail), 1 (limp tail), 2 (mild palsy of one or both hind legs), 3 (severe palsy of one or both hind legs), 4 (complete paralysis of one or both hind legs), 5 (paralysis of one or both hindlimbs and the beginning of paralysis of the forelimbs) and 6 (moribund). Animals

Table 1 Affinity binding and rate constants of llantide, interleukin $1 \beta$ and interleukin 1 receptor antagonist to interleukin 1 receptor type $\mathrm{I}^{\mathrm{a}}$

\begin{tabular}{lccc}
\hline Ligands & $\mathbf{k}_{\mathbf{a}}\left(\mathbf{M}^{-\mathbf{1}} \mathbf{s}^{-\mathbf{1}}\right)$ & $\mathbf{k}_{\mathbf{d}}\left(\mathbf{s}^{\mathbf{- 1}}\right)$ & $\mathbf{K}_{\mathbf{d}}(\mathbf{M})$ \\
\hline llantide & $1.84 \pm 0.20 \times 10^{5}$ & $2.69 \pm 0.58 \times 10^{-3}$ & $2.75 \times 10^{-8} \pm 7.86 \times 10^{-9}$ \\
IL-1Ra & $1.47 \pm 5.53 \times 10^{5}$ & $3.62 \pm 0.65 \times 10^{-3}$ & $4.80 \times 10^{-8} \pm 1.32 \times 10^{-8}$ \\
IL-1 $\beta$ & $8.56 \pm 2.79 \times 10^{5}$ & $7.53 \pm 2.03 \times 10^{-4}$ & $1.71 \times 10^{-7} \pm 7.07 \times 10^{-9}$
\end{tabular}

aL-1 $\beta$, interleukin $1 \beta$; IL-1Ra, interleukin 1 receptor antagonist. 
with a clinical score $\geq 4$ were immediately killed. From dpi 10 forward, the animals were treated once daily for 5 consecutive days with Ilantide-t $(10 \mathrm{mg} / \mathrm{kg}, 1 \mathrm{ml} / \mathrm{kg}$, s.c.) or PBS $(1.0 \mathrm{ml} / \mathrm{kg}$ s.c.). Only animals that reached a clinical score $\geq 1$ before dpi 14 were included in the study.

\section{Data analysis}

The statistical analysis was performed using one-way analysis of variance (ANOVA) followed by the Newman-Keuls multiple-comparisons post hoc test or two-way ANOVA followed by the Bonferroni post hoc test, a nonparametric $t$-test and a one-sample $t$-test when appropriate (GraphPad Prism 5 software; GraphPad Software, La Jolla, CA, USA).

\section{Results}

Ilantide, a peptide modeled after the IL-1Ra binding site for IL-1RI, binds to the ectodomain of IL-1RI with an affinity comparable to the cytokine

Using a model of the tertiary structure of the IL-1RaIL-1RI complex [PDB:1IRA] [19], we designed a peptide ten amino acids long from the $N$ terminus of IL-1Ra, termed Ilantide (IL-1 antagonistic peptide), a part of the

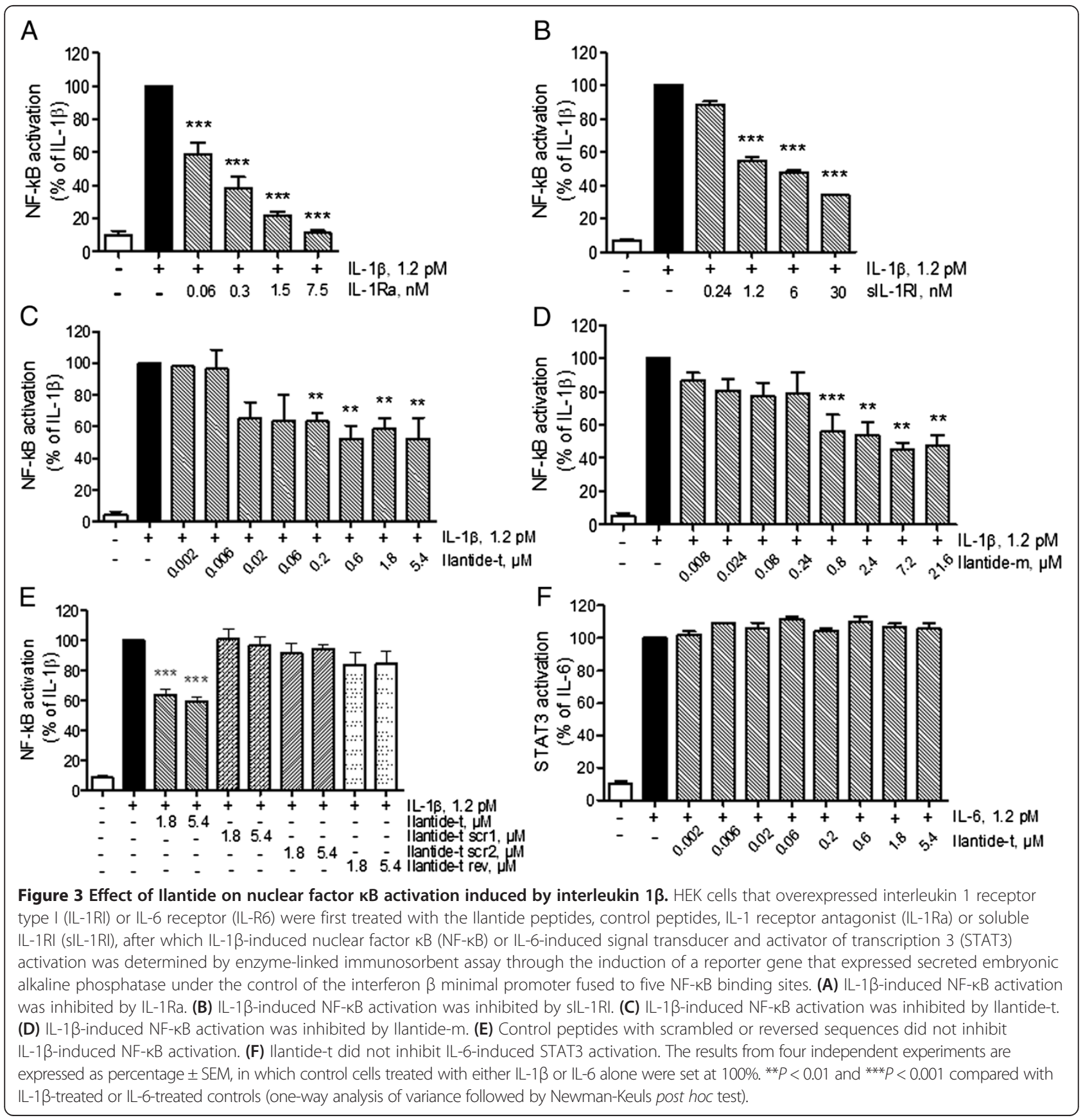


IL-1Ra protein that interacts with the Ig3 module of the type I receptor (Figure 1). We studied the binding of the peptide to IL-1RI by surface plasmon resonance (SPR) analysis. IL-1 $\beta$ and IL-Ra were used as positive controls. Ilantide-t, IL-1 $\beta$ and IL-1Ra bound to IL-1RI (Figures $2 \mathrm{~A}$ to $2 \mathrm{C}$ ). The calculated affinity and rate constants of these interactions are shown in Table 1. IL-1Ra and Ilantide-t bound IL-1RI with apparent $K_{d}$ values within the same order of magnitude $\left(4.8 \times 10^{-8} \mathrm{M}\right.$ and $2.75 \times 10^{-8} \mathrm{M}$, respectively), whereas IL-1 $\beta$ had a lower affinity for the receptor $\left(1.71 \times 10^{-7} \mathrm{M}\right)$. As a control, we also measured the binding of Ilantide-t, IL-1 $\beta$ and Il-1Ra to a control Ig-like module molecule that consisted of the double-Ig module of NCAM and found no significant binding (Figures $2 \mathrm{~A}$ to $2 \mathrm{C}$ ). Ilantide-t dose-dependently inhibited the binding between IL-1RI and IL-1 $\beta$ (Figure 2D), indicating that IL-1 $\beta$ and Ilantide competed for the same binding site in IL-1RI. llantide inhibits the interleukin $1 \beta$-induced activation of nuclear factor $\mathrm{KB}$

The NF-kB signaling pathway plays a central role in the regulation of IL-1-mediated inflammation [20]. We assumed that Ilantide might inhibit NF- $\mathrm{kB}$ activation induced by IL- $1 \beta$ because of the ability of Ilantide to outcompete IL-1RI-IL-1 $\beta$ binding (Figure 2D). To test this hypothesis, HEK cells that overexpressed IL-1RI were used. NF- $\mathrm{KB}$ activation was induced by IL-1 $\beta$. The cells were treated with Ilantide, control peptides, IL-1Ra or sIL-1RI, and the activation of NF- $\mathrm{kB}$ was determined by ELISA. Similarly to IL-1Ra and sIL-1RI, both Ilantide-m and Ilantide-t dose-dependently inhibited NF- $\mathrm{B}$ activation induced by IL-1 $\beta$ (Figures $3 \mathrm{~A}$ to $3 \mathrm{D}$ ), whereas the scrambled and reversed Ilantide-t peptides had no effect (Figure 3E). In contrast, Ilantide-t did not inhibit STAT3 activation induced by IL-6 (Figure 3F), suggesting that Ilantide specifically inhibits NF-kB activation induced by IL-1 $\beta$ through binding to IL-1RI.

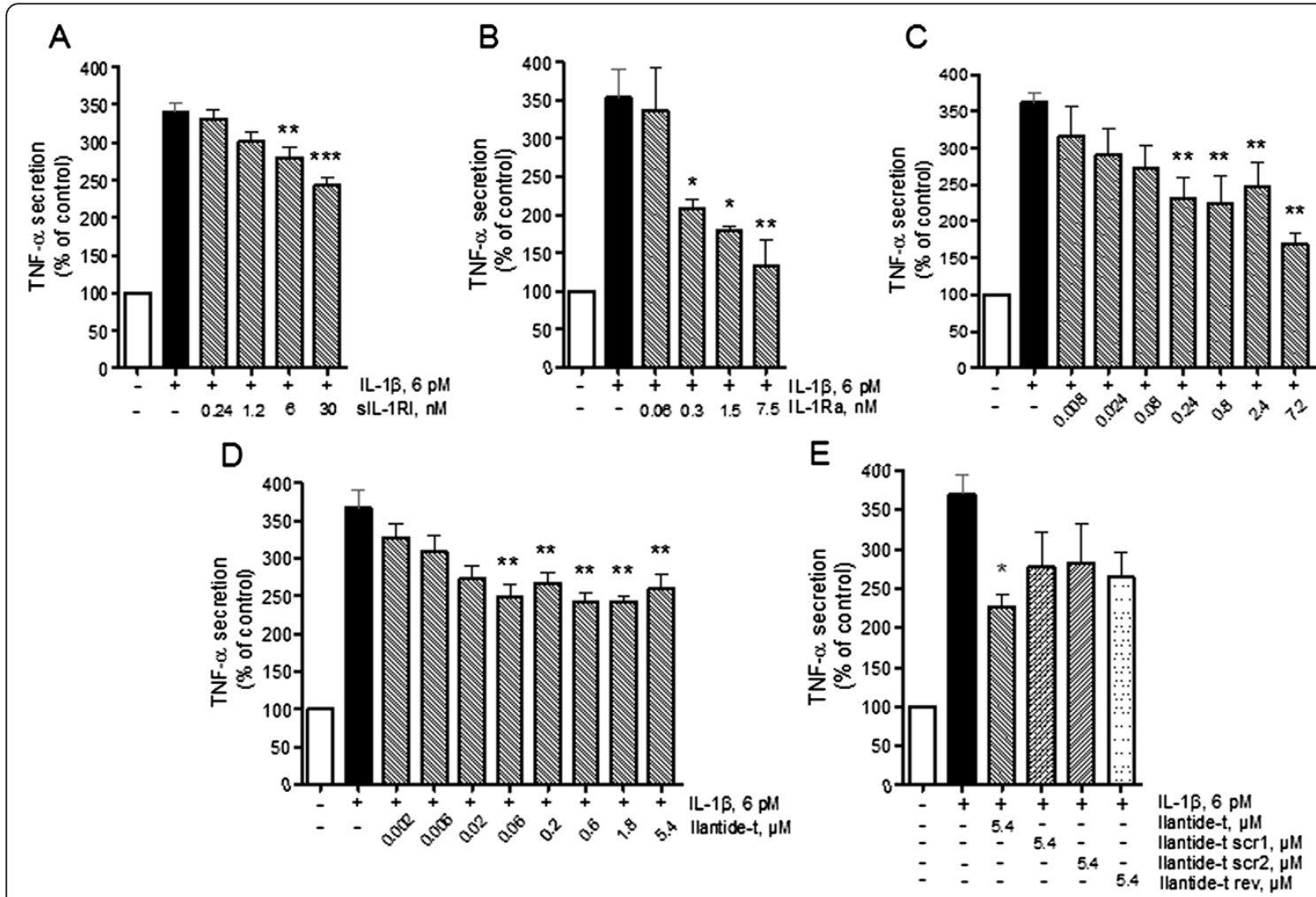

Figure 4 Effect of llantide on tumor necrosis factor a release from interleukin $1 \beta$-activated macrophages. AMJ2-C8 macrophages were exposed to interleukin $1 \beta$ (IL-1 $\beta$ ) and treated with llantide peptides, control peptides, IL-1 receptor antagonist (IL-1Ra) or soluble IL-1RI (sIL-1RI) for 24 hours. The conditioned medium from macrophages was used to treat fibroblast cells for 24 hours, and the amount of tumor necrosis factor a (TNF-a) in the conditioned medium was evaluated on the basis of fibroblast cell survival in the presence of actinomycin D. (A) TNF-a release from IL-1 $\beta$-activated macrophages was inhibited by IL-1Ra. (B) TNF-a release from IL-1 $\beta$-activated macrophages was inhibited by sIL-1RI. (C) TNF-a release from IL-1 $\beta$-activated macrophages was inhibited by llantide-t. (D) TNF-a release from IL-1 $\beta$-activated macrophages was inhibited by llantide-m. (E) Scrambled (scr) or reverse sequence control peptides did not inhibit TNF-a release from IL-1 $\beta$-activated macrophages. The results from four independent experiments are expressed as percentage \pm SEM with untreated controls set at $100 \%$. ${ }^{*} P<0.05$, ${ }^{* *} P<0.01$ and ${ }^{* *} P<0.001$ compared with macrophages treated with IL-1 $\beta$ only (one-way analysis of variance followed by Newman-Keuls post hoc test). 
llantide inhibits interleukin $1 \beta$-induced secretion of tumor necrosis factor $\boldsymbol{\alpha}$ in macrophages

Macrophages are activated by $\mathrm{T}$ lymphocytes, resulting in the production of proinflammatory cytokines (for example, TNF- $\alpha$ and IL-1 $\beta$ ). These cytokines trigger inflammatory cascades, thus leading to the activation of inflammation $[21,22]$. To test whether Ilantide, IL-1 $\beta$ or IL-1Ra would reduce TNF- $\alpha$ release from IL- $1 \beta$ activated macrophages, we used a mouse-derived macrophage cell line, AMJ2-C8. The cells were pretreated with Ilantide, control peptides, IL-1Ra, sIL-1R or hydrocortisone and stimulated by IL- $1 \beta$ or IFN- $\gamma$. The conditioned medium from the macrophages was used to treat L929 cells, which, in the presence of actinomycin D, are sensitive to picomolar concentrations of TNF- $\alpha$ [12]. The amount of TNF- $\alpha$ in the conditioned medium was calibrated against fibroblasts exposed to standard concentrations of TNF- $\alpha$. As expected, IL- $1 \beta$-induced macrophage TNF- $\alpha$ production was completely inhibited by $100 \mu \mathrm{M}$ hydrocortisone (data not shown). Similarly to IL-1Ra and sIL-1RI, Ilantide-m and Ilantide-t significantly inhibited IL- $1 \beta$-induced TNF- $\alpha$ secretion in macrophages (Figures $4 \mathrm{~A}$ to $4 \mathrm{D}$ ), whereas the scrambled Ilantide peptides had no statistically significant effect (Figure 4E).

\section{Ilantide promotes the survival of primary neurons}

IL-1 mediates neuronal cell death during acute brain injury [23], and IL-1Ra has neuroprotective effects on cerebral ischemia, excitotoxicity and brain trauma in various rodent models [24,25]. Therefore, we tested whether Ilantide or IL-1Ra promotes neuronal cell survival. Cerebellar granule neurons from 7-day-old rats were differentiated for 7 days in a high-potassium medium, after which the neurons were grown for 2 days in a low-potassium medium either the presence or absence of insulin-like growth factor 1 (IGF-1; positive control), Ilantide-m, Ilantide-t, IL-1Ra or IL$1 \beta$. Cell death induced by potassium withdrawal was inhibited by IGF-1 (Figure 5A). Treatment with IL$1 \mathrm{Ra}$, Ilantide-m and Ilantide-t, but not IL-1 $\beta$, concentration-dependently promoted CGN survival (Figure 5). These results indicate that the inhibition of IL-1RI in CGNs leads to an increase in neuronal cell survival.

\section{Ilantide stimulates neuritogenesis in cultures of primary neurons}

IL-1RI is widely expressed in the central nervous system, including cerebellar, hippocampal and hypothalamic neurons [26,27]. The firing rate of anterior hypothalamic neurons is inhibited by IL- $1 \beta$ exposure [28]. To test the effects of Ilantide-t, IL-1 $\beta$, IL-1Ra and sIL-1RI on neuronal differentiation, CGNs were grown on fibroblast cells in the absence or presence of these compounds at various concentrations. We found that Ilantide-t, IL-1Ra and sIL-1RI significantly induced neurite outgrowth from 7-day-old CGNs in a dose-dependent manner (Figures 6A to $6 \mathrm{C}$ ), whereas IL-1 $\beta$ did not have neuritogenic effects (Figure 6D).

We subsequently tested whether IL-1 $\beta$ interferes with the neuritogenic effect of Ilantide and IL-1Ra. IL-1 $\beta$ at
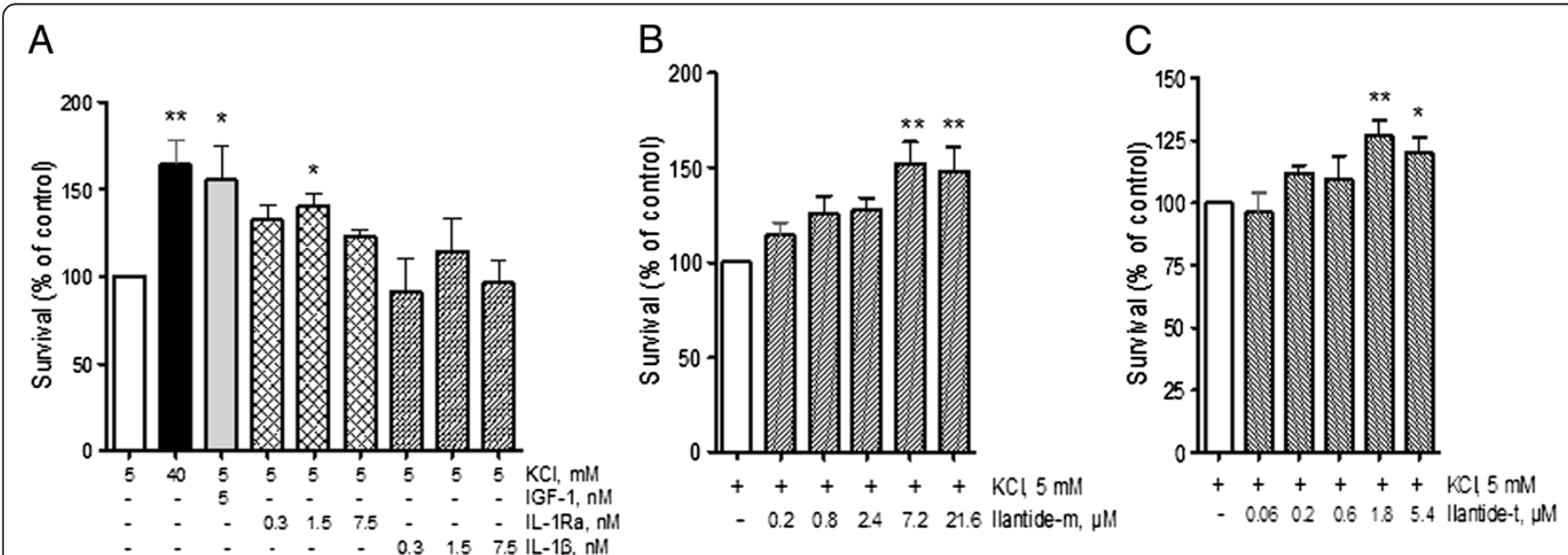

Figure 5 Effect of Ilantide and interleukin 1 receptor antagonist on survival of cerebellar granule neurons induced to undergo apoptosis. The neurons were allowed to differentiate for 7 days in a high-potassium (40 mM) medium before apoptosis was induced by changing to a low-potassium medium (5 mM). Survival was estimated 48 hours later. (A) The effect of insulin-like growth factor 1 (IGF-1), interleukin 1 receptor antagonist (IL-1Ra) and IL-1 3 on cerebellar granule neuron (CGN) apoptosis induced by 5 mM KCl. (B) The effect of Ilantide-m on CGN apoptosis induced by $5 \mathrm{mM} \mathrm{KCl}$. (C) The effect of Ilantide-t on CGN apoptosis induced by $5 \mathrm{mM}$ KCl. The results from at least four independent experiments are expressed as mean \pm SEM with untreated cultures induced to undergo apoptosis by $5 \mathrm{mM}$ KCl set at $100 \%$. ${ }^{*} P<0.05$ and ${ }^{* *} P<0.01$ compared with untreated cultures induced to undergo apoptosis (one-way analysis of variance followed by Newman-Keuls post hoc test). 

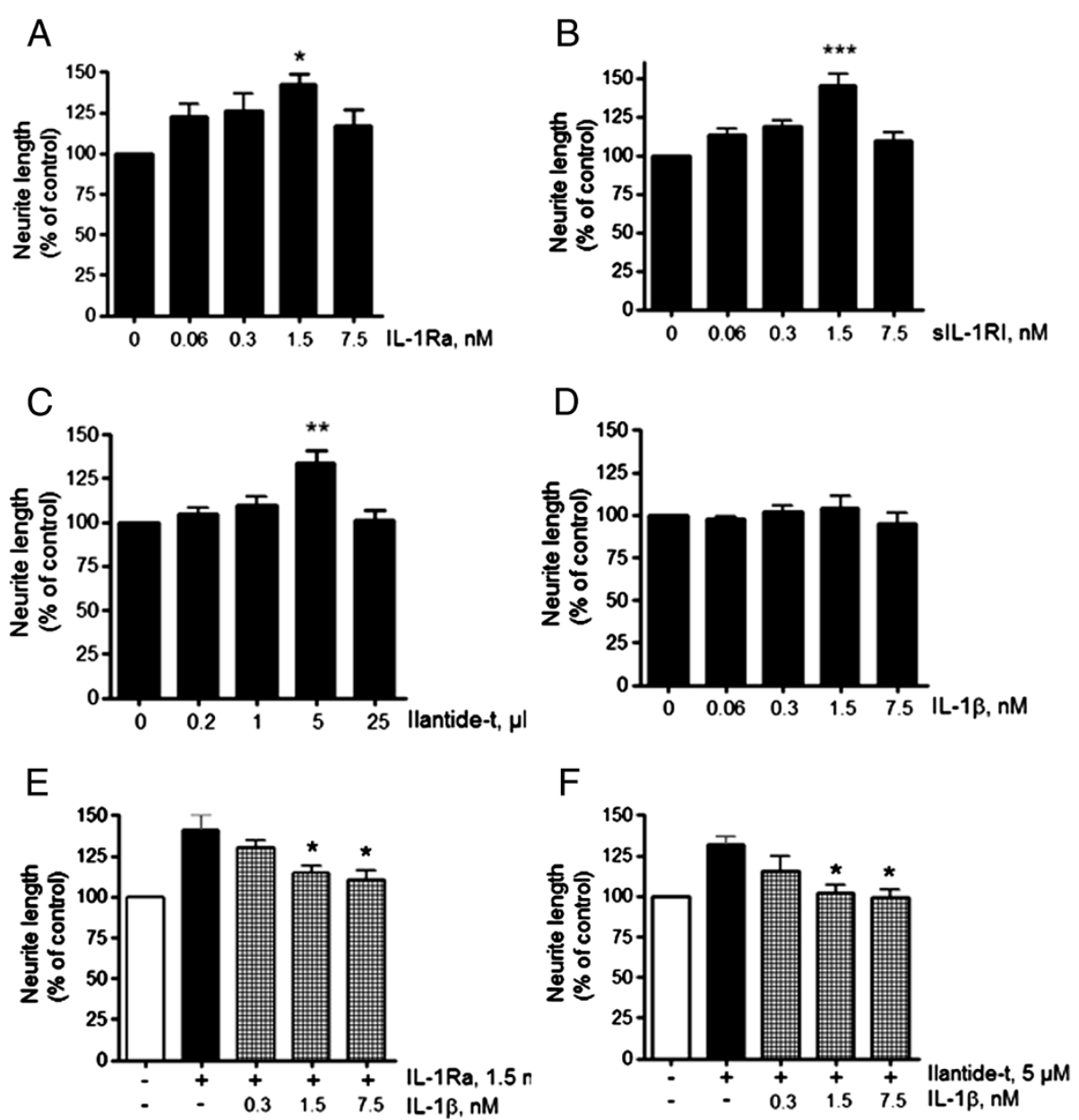

Figure 6 Effect of llantide on neurite outgrowth from cerebellar granule neurons. Cerebellar granule neuron cultures were treated with interleukin 1 receptor antagonist (IL-1Ra) (A), soluble interleukin 1 receptor type I (sIL-1RI) (B), llantide-t (C) or IL-1 3 (D) for 24 hours. The cultures were fixed and immunostained with rabbit anti-rat growth-associated protein 43 (anti-GAP-43) primary antibodies and then with secondary Alexa Fluor 488 goat anti-rabbit antibodies. (E) Effect of IL-1 $\beta$ on neurite outgrowth induced by IL-1Ra. (F) Effect of IL-1 $\beta$ on neurite outgrowth induced by llantide-t. The results from three to four independent experiments are expressed as percentage \pm SEM with untreated controls set at $100 \%$, corresponding to an average neurite length of $19.3 \pm 4.1 \mu \mathrm{m} .{ }^{*} P<0.05$ and ${ }^{*} P<0.01$ compared with untreated controls (A to D) or cultures treated with either IL-1Ra or Ilantide alone ( $E$ and F) by one-way analysis of variance followed by the Newman-Keuls post hoc test).

concentrations of $1.5 \mathrm{nM}$ and $7.5 \mathrm{nM}$ significantly inhibited the neuritogenic effect of both IL-1Ra and Ilantide-t (Figures 6E and 6F). Thus, the inhibition of IL-1R signaling resulted in the stimulation of neurite outgrowth.

Ilantide protects rat pancreatic islets from interleukin $1 \beta$-induced apoptosis independently of nitric oxide

To investigate the effectiveness and potency of Ilantide in inhibiting IL-1-induced primary rat islet apoptosis, Ilantide was added at a concentration of $8.68 \times 10^{n} \mathrm{nM}$ as indicated prior to exposure to a known proapoptotic concentration of IL-1 $\beta$ of $8.68 \mathrm{nM}(150 \mathrm{pg} / \mathrm{ml})$ [29]. Consistent with previous findings [30], we observed that a maximally protective effect of Ana of $64 \%$ inhibition against IL-1 $\beta$-induced apoptosis was obtained at a concentration of $8.68 \times 10^{4} \mathrm{nM}$ (Figure 7A), and this condition was used as a positive control in the experiments with Ilantide.

Ilantide-m maximally inhibited IL-1 $\beta$-induced apoptosis by $49 \%$ at $8.68 \times 10^{3} \mathrm{nM}$ (Figure $7 \mathrm{~B}$ ). Ilantide-t was a more effective antagonist of IL-1 $\beta$-induced apoptosis, with 93\% inhibition, exceeding the antagonistic effect of Ana, although Ilantide-t had lower potency $\left(8.68 \times 10^{6} \mathrm{nM}\right)$ (Figure $\left.7 \mathrm{C}\right)$.

In addition to preventing IL- $1 \beta$-induced $\beta$-cell apoptosis, Ana inhibits IL-1 $\beta$-induced nitric oxide production [29]. Interestingly, none of the Ilantide peptides significantly inhibited IL-1 $\beta$-induced nitric oxide production at the concentrations that reduced IL-1 $\beta$-induced apoptosis (Figure 8). 


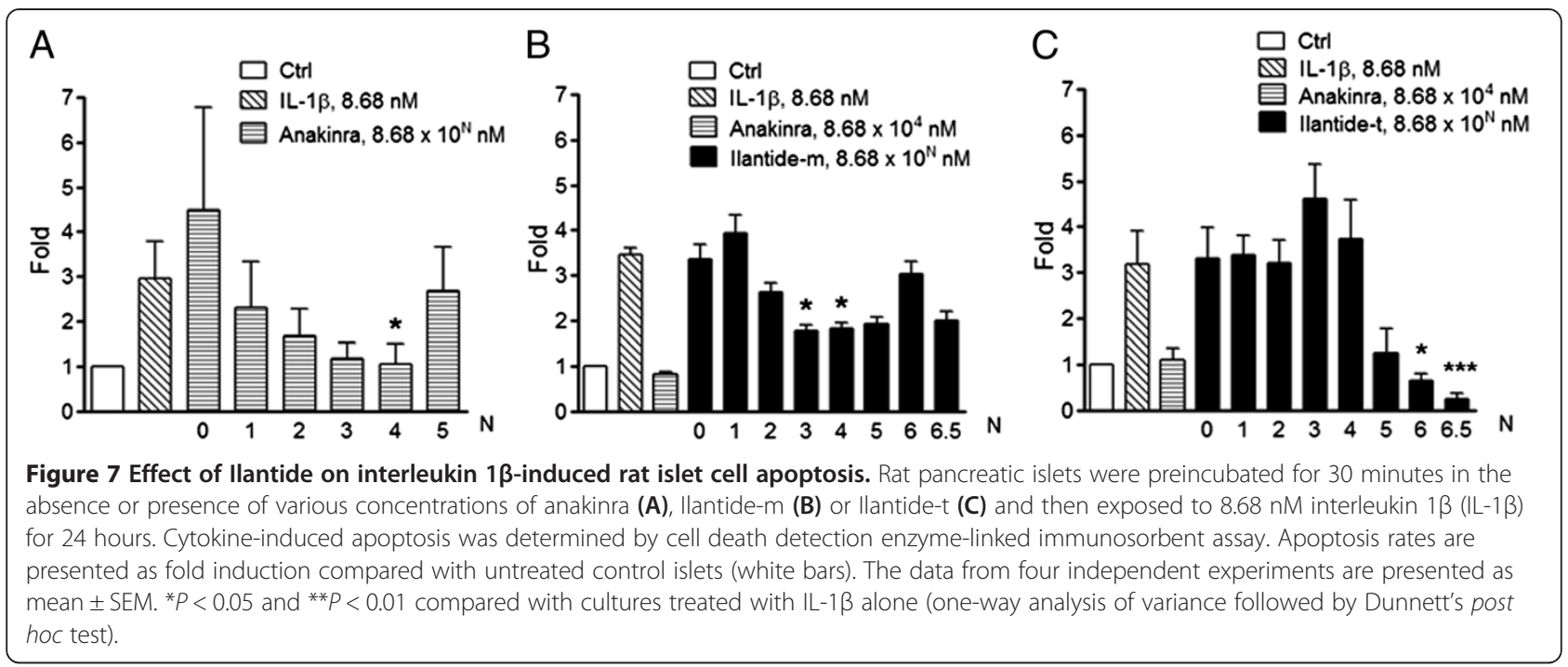

Ilantide crosses the blood-brain barrier

The time course of the peptide concentrations in plasma samples collected from rats after a single subcutaneous injection at a $10 \mathrm{mg} / \mathrm{kg}$ dose is shown in Figure 9. Ilantide-t was detected in plasma 20 minutes after administration $(5,816 \pm 44 \mathrm{ng} / \mathrm{ml})$ and remained detectable for up to 30 hours $(111 \pm 3.3 \mathrm{ng} / \mathrm{ml})$. Twenty minutes after subcutaneous administration, the peptide concentration in plasma averaged approximately $6 \mu \mathrm{g} / \mathrm{ml}$, and its half-life was calculated as approximately 2 hours. The peptide concentration in CSF was $125 \pm 13 \mathrm{ng} / \mathrm{ml} 30$ minutes after systemic administration. Thus, the ratio between the Ilantide concentration in plasma (measured at 20 minutes) and the Ilantide concentration in CSF (measured at 30 minutes) was 55.

Ilantide reduces inflammation in collagen-induced arthritis model

IL-1 is a major pathogenic cytokine in the development of rheumatoid arthritis [31]. The concentration of IL-1 in sera of rats with CIA is already elevated during the preclinical stage of the disease, and it reaches a maximal level during the first 4 to 5 days after disease onset [32]. Therefore, we used a treatment regimen that specifically covered this period. Figure 10 illustrates the dynamics of the clinical state (Figure 10A) and cumulative clinical scores (Figure 10B) in rats with CIA. Ilantide-t significantly attenuated the severity of CIA on dpi 10 to 16 compared with the vehicle-treated group $(t=2.1, d f=31 ; P<0.05$ by unpaired $t$-test).

\section{Ilantide strongly reduces lipopolysaccharide-induced behavioral changes}

Two-way ANOVA did not reveal significant differences between the veh/veh, veh/Ila and veh/Ana groups $\left(F_{2,72}=1.04\right.$, $P=0.37$ ), indicating that Ilantide-t and Ana did not modify social behavior per se (Figure 11A). LPS significantly depressed social activity for 8 hours following compound administration $\left(F_{1,72}=54.59\right.$, veh/veh vs. LPS/veh; $\left.P<0.0001\right)$. Ilantide-t counteracted the onset of sickness behavior and attenuated social depression compared with vehicle-treated animals $\left(F_{1,76}=13.92\right.$, LPS/veh vs. LPS/Ila; $\left.P=0.001\right)$. No
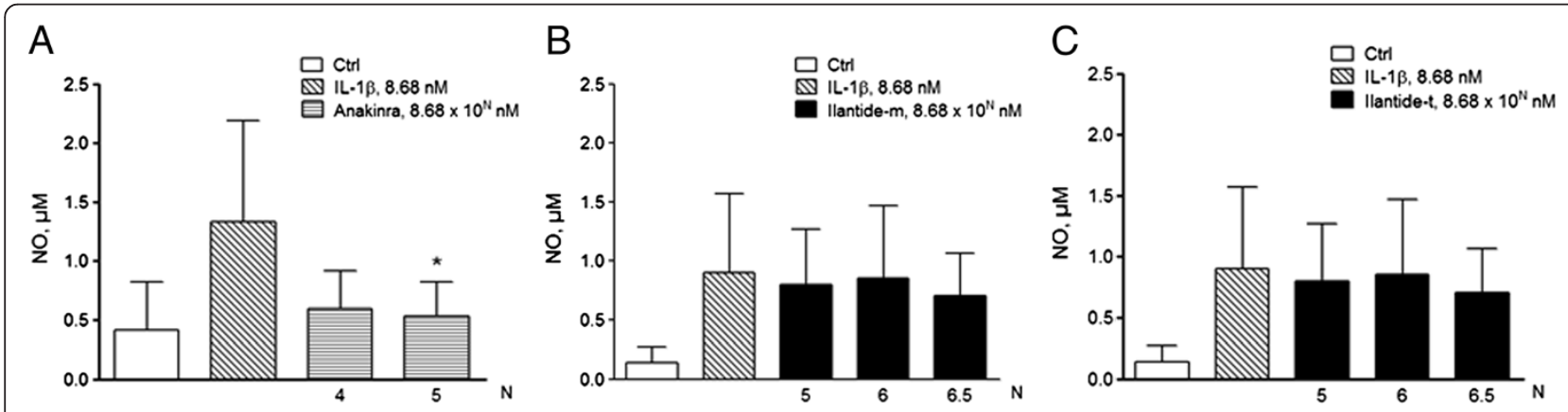

Figure 8 Effect of Ilantide on interleukin $1 \beta$-induced nitric oxide production. Anakinra (A) but none of the peptides, llantide-m (B) or llantide-t (C), inhibited interleukin $1 \beta$ (IL-1 $\beta$ )-induced nitric oxide production. Nitrites were measured in the supernatants using data derived from the experiments presented in Figure 7. The results of four independent experiments are shown. ${ }^{*} P<0.05$ and ${ }^{* *} P<0.01$ compared with cultures treated with IL-1 alone (one-way analysis of variance followed by Dunnett's post hoc test). 


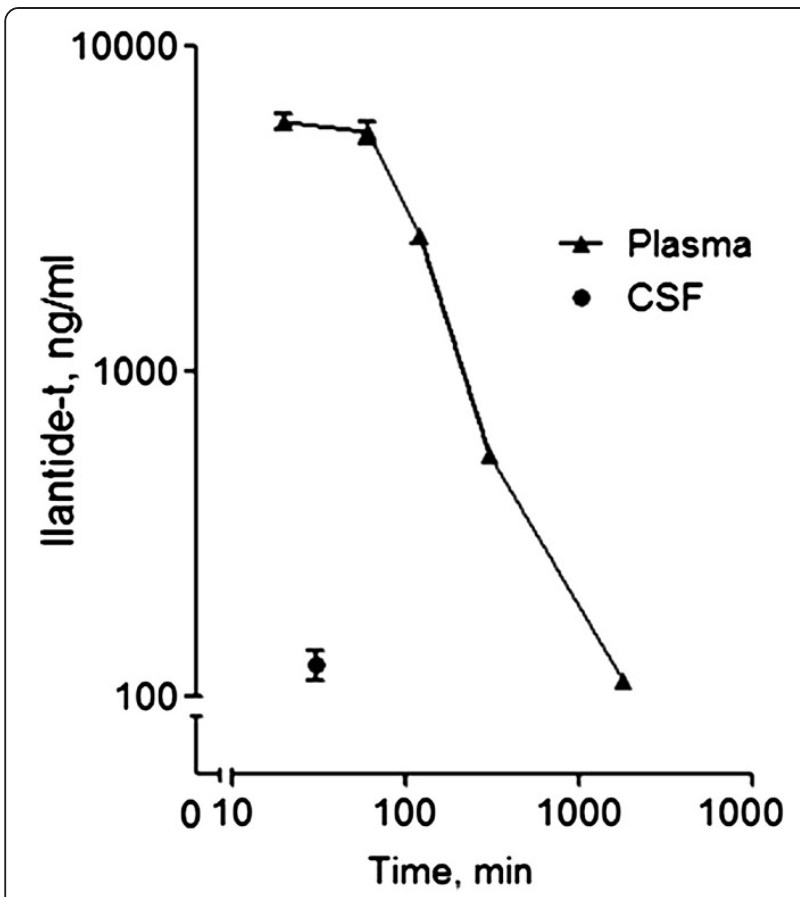

Figure 9 Time course of llantide concentration in plasma and cerebrospinal fluid after a single subcutaneous injection of 10 $\mathbf{m g} / \mathbf{k g}$. Peptide concentrations were measured by performing a competitive enzyme-linked immunosorbent assay. The data are expressed as mean \pm SEM. CSF, cerebrospinal fluid. significant effect of Ana on sickness behavior was observed (Figure 11B).

One-way ANOVA showed that LPS decreased body weight 24 hours after LPS injection $(P<0.001$, LPS/veh vs. Veh/Veh, Newman-Keuls post hoc test). Ilantide-t and Ana attenuated the anorexigenic effect of LPS $(P<0.05$, LPS/veh vs. LPS/Ila and LPS/veh vs. LPS/Ana, NewmanKeuls post hoc test) (Figure 11C). The effect of Ilantide-t on LPS-induced sickness behavior was accompanied by an increase in IL-10 plasma levels 2 hours after LPS administration $\left(F_{1,42}=6.03, P<0.01\right)$ (Figure $\left.11 \mathrm{D}\right)$. There was a tendency toward reduction of levels of proinflammatory cytokines (IL-6 and IFN- $\gamma$ ) 6 hours following LPS injection, although the effect was not statistically significant (Figure 11D).

\section{Ilantide delays clinical signs of experimental autoimmune enchephalomyelitis}

To further investigate the effect of Ilantide on neuroinflammation, EAE (that is, an animal model of multiple sclerosis) was induced in rats by injecting MBP in CFA. Following the induction of EAE, the animals' weight, clinical signs of EAE and survival were recorded. The first clinical signs of EAE appeared on dpi 10. From dpi 10 to 14, the animals were treated daily with either Ilantide or vehicle. Treatment with Ilantide-t had no significant effects on weight change or survival (data not shown). As shown in Figure 12, however, the clinical signs of EAE were attenuated by Ilantide-t. In Figure 12, the data from individual animals are aligned according to the first appearance of clinical signs. On the first and second days,
A

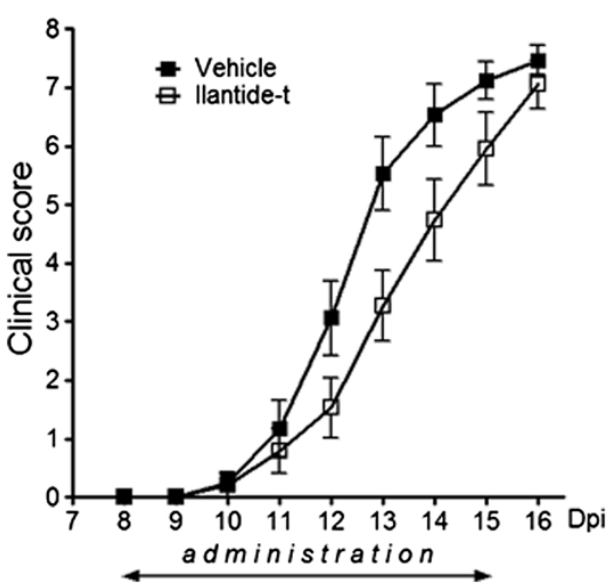

B

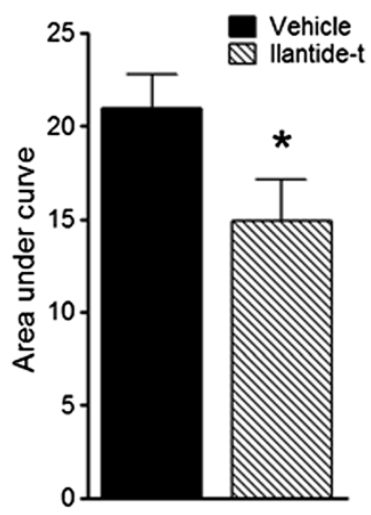

Figure 10 llantide attenuates the severity of arthritis in animals with collagen-induced arthritis. (A) Collagen-induced arthritis was induced by an intradermal injection of $250 \mu \mathrm{g}$ of collagen II emulsified in complete Freund's adjuvant (125 $\mu \mathrm{g} \mathrm{M}$. tuberculosis). On day postimmunization 8 (dpi 8), before the onset of clinical signs, all of the animals were randomly divided into two groups and subcutaneously dosed daily for 8 days (dpi 8 to 15) with $10 \mathrm{mg} / \mathrm{kg}$ llantide-t $(n=17)$ or $1 \mathrm{ml} / \mathrm{kg}$ phosphate-buffered saline vehicle $(n=16)$. (B) To evaluate cumulative clinical scores during the entire treatment period, the values are expressed as the area under the curve for each group during dpi 10 to 15 with the baseline set at dpi 8 . The data are expressed as mean \pm SEM. ${ }^{*} P<0.05$ by unpaired $t$-test. 

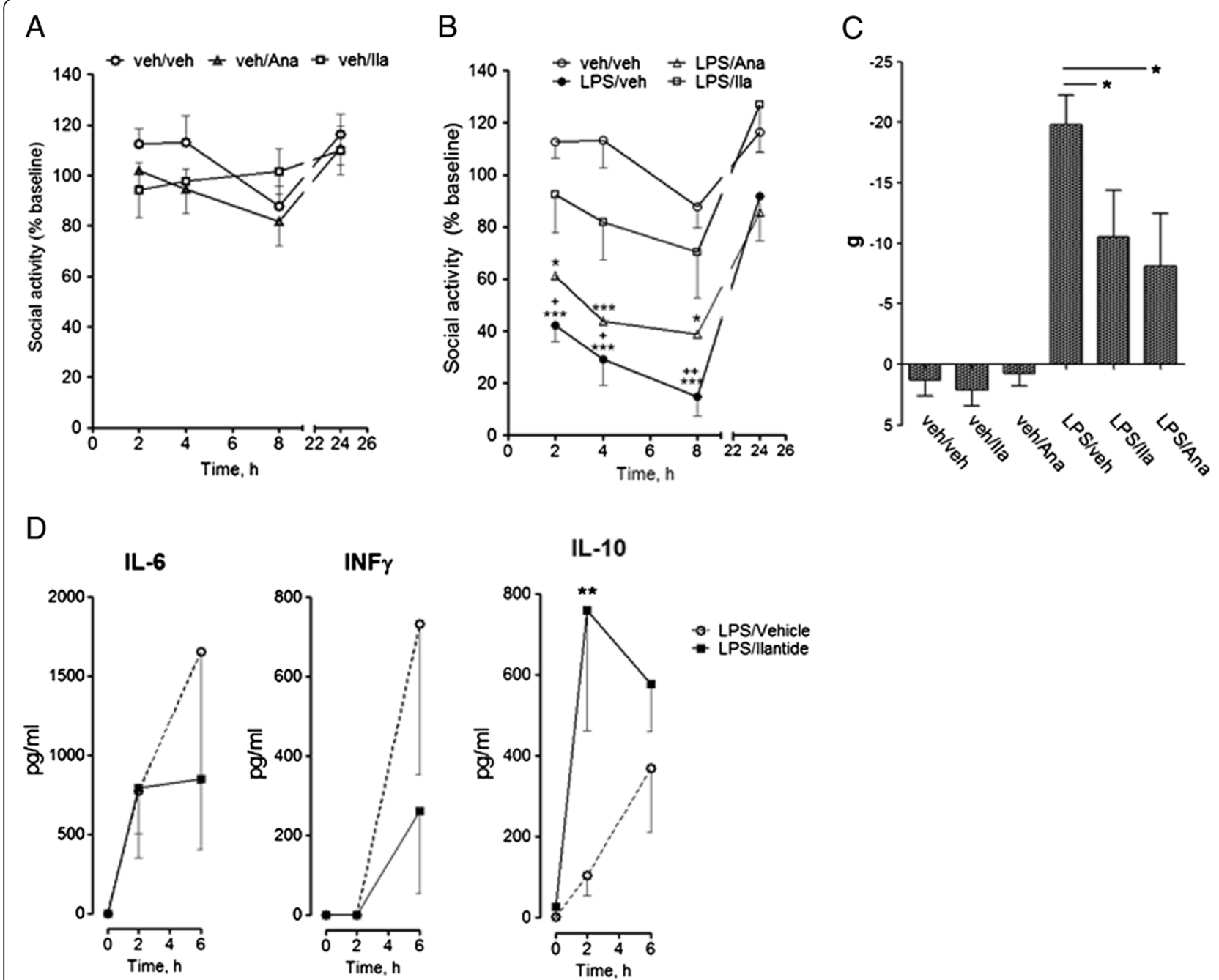

Figure 11 llantide attenuates the decrease in social activity and increases plasma levels of interleukin 10 in lipopolysaccharideinduced neuroinflammation. Ilantide-t (lla; $10 \mathrm{mg} / \mathrm{kg}$ ), anakinra (Ana; $100 \mathrm{mg} / \mathrm{kg}$ ) or vehicle (Veh; $1 \mathrm{ml} / \mathrm{kg}$ ) was subcutaneously injected simultaneously with an intraperitoneal injection of either lipopolysaccharide (LPS) $(250 \mu \mathrm{g} / \mathrm{kg})$ or vehicle $(1 \mathrm{ml} / \mathrm{kg})$. Baseline social activity was recorded for 4 minutes for all of the animals at 0 hours. The duration of social interaction at each time point is expressed as a percentage of baseline values and was averaged for each experimental group. The data are expressed as mean \pm SEM. (A) Social activity of rats in control groups. (B) Social activity of rats in LPS-treated and veh/veh groups (SEM for LPS/Ana group not presented). ${ }^{*} P<0.05$ and ${ }^{* * *} P<0.001$ compared with control (veh/veh). ${ }^{+} P<0.05$ and ${ }^{++} P<0.01$ compared with LPS/lla group. (C) Weight gain is expressed as the difference from the body weight measured at 0 and 24 hours after LPS injection. ${ }^{*} P<0.05$ (one-way analysis of variance (ANOVA) followed by Newman-Keuls post hoc test). (D) Plasma levels of interleukin 6 (IL-6), interferon $\gamma$ and IL-10. ${ }^{*} P<0.01$ (B and D), by two-way ANOVA followed by Bonferroni post hoc test.

the mean clinical signs were significantly lower in Ilantide$\mathrm{t}$-treated animals than in vehicle-treated animals. At later time points, however, no difference was found between the mean clinical signs in the two groups. These results show that the treatment of EAE with Ilantide attenuated, but did not prevent, the development of EAE.

\section{llantide reduces social memory deficits induced by amyloid- $\beta$}

$A \beta$ is known to induce deficits in social memory. Therefore, we tested whether Ilantide can rescue $A \beta$-induced social memory impairment. The rats were administered $\mathrm{A} \beta_{25-35}$, followed by administration with either Ilantide$t$ or vehicle. No significant intergroup difference in social activity was observed during the first trial, suggesting that $A \beta$ and Ilantide-t did not influence investigatory activity per se $\left(F_{2,32}=0.94 ; P=0.4\right.$ by one-way ANOVA) (data not shown). Social memory was measured as a decrease in the time that an adult rat spent investigating the same (that is, familiar) juvenile during the second trial compared with the first trial. The social recognition $R R_{\text {familiar }}$ value was $<0.5$ in the untreated 


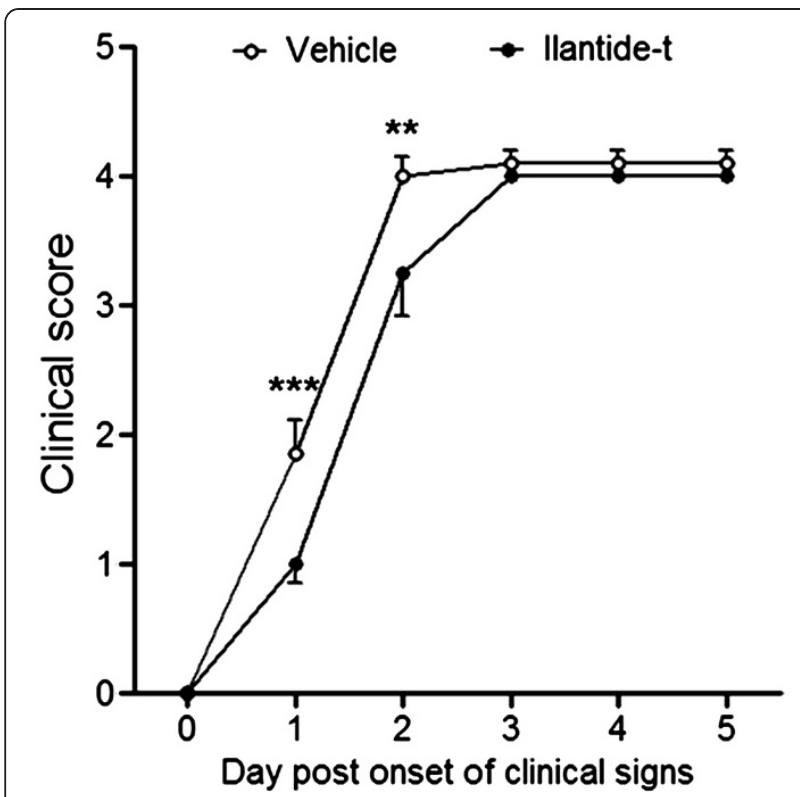

Figure 12 llantide delays the progression of experimental autoimmune encephalomyelitis. Experimental autoimmune encephalomyelitis (EAE) was induced in 30 animals, from among which 22 developed clinical signs of EAE (12 from the control group and 10 from the group treated with Ilantide-t). Clinical signs were evaluated daily. All of the data were aligned according to the onset of clinical signs and are presented as mean \pm SEM. When the animals were killed, their clinical scores on the day they were killed were maintained at all subsequent time points. ${ }^{* *} P<0.01$ and ${ }^{* * *} P<0.001$ (two-way repeated-measures analysis of variance followed by the Bonferroni post hoc test).

group $(t=7.67, d f=10 ; P<0.0001$ by one-sample $t$-test) (Figure 13). Animals in the $A \beta /$ veh group exhibited a significant deficit in social memory. The rats in this group failed to recognize the juvenile during the second trial. $\mathrm{RR}_{\text {familiar }}$ did not differ from $0.5(t=0.44, d f=11 ; P=0.67$ by one-sample $t$-test) and significantly differed from the $\mathrm{RR}_{\text {familiar }}$ in the control group $(P<0.001$ by one-way ANOVA followed by the Newman-Keuls post hoc test). Treatment with Ilantide-t counteracted the development of cognitive impairment. The $R_{\text {familiar }}$ in this group was significantly lower than the theoretical value of 0.5 ( $t=4.12, d f=11 ; P=0.002$ by one-sample $t$-test) and the value in the $A \beta /$ veh group $(P<0.05$ by one-way ANOVA followed by the Newman-Keuls post hoc test). The $A \beta /$ Ilantide-treated rats were still able to recognize a new, unfamiliar juvenile during the third trial (that is, the $R_{\text {new }}$ value did not differ from 0.5$)(t=0.7, d f=11 ; P=0.5$ by one-sample $t$-test), indicating that Ilantide ameliorated the social memory deficit in A $\beta$-treated animals.

\section{Discussion}

A critical role for IL-1 in the pathogenesis of acute and chronic inflammation has been well-documented [33-35].
IL-1RI blockade is one of the current strategies used in the treatment of IL-1-induced conditions [1], and an IL-RI receptor antagonist, Ana, has already been approved for the treatment of some of these conditions. Despite the high efficacy of Ana, however, this drug has some disadvantages, such as a short-lasting therapeutic effect in 20\% of patients with rheumatoid arthritis [36], local injection reactions (for example, erythema, ecchymosis, inflammation and pain [37]) and in some cases depression [38]. Furthermore, the absence of an effect of peripheral administration of Ana on neuroinflammation observed in the present study should be added to the list of Ana's disadvantages, although further testing with other Ana doses is needed to substantiate this finding.

The aim of the present study was to develop a synthetic low-molecular-weight antagonist of IL-1RI that is effective in the treatment of not only peripheral inflammation but also neuroinflammation. We found that a peptide termed Ilantide, derived from the $N$ terminus of human IL-1Ra, mimics important characteristics of IL-1Ra. Thus, Ilantide binds to IL-1RI with an affinity comparable to that of IL-1Ra and with higher affinity than IL-1 $\beta$. Importantly, Ilantide inhibits the binding of IL-1 $\beta$ to IL-1RI. Signaling from the IL-1/IL-1RI/Il-1RAcP complex is known to activate the NF-kB pathway [20]. We found that Ilantide inhibited NF- $\mathrm{kB}$ activation. We also found that Ilantide, similarly to IL-1Ra, inhibited the secretion of TNF- $\alpha$ by macrophages, thus antagonizing an important mechanism of the proinflammatory action of IL-1.

IL-1 induces apoptosis in insulin-producing pancreatic $\beta$-cells, and the administration of Ana in patients with type 2 diabetes mellitus improves $\beta$-cell function [39]. We investigated the protective potency of Ilantide against the IL-1-induced apoptosis of pancreatic islets and compared it to the potency of Ana. Ilantide-t in high molar excess reduced IL-1-induced apoptosis by 93\%, which was $1.5 \times$ the maximal effect of Ana. Unlike Ana, however, the effect of Ilantide was not associated with inhibition of IL-1-induced nitric oxide production, which is consistent with the less effective inhibition of NF- $\mathrm{KB}$ activation compared with IL-1Ra (Figures 3A and 3C). The molecular mechanism that underlies this discrepancy is unclear, but it may be related to the lower steric hindrance that Ilantide exerts on the IL-1/IL-1RT1/IL1 RAcP interaction complex compared with IL-1Ra, thus allowing the escape of certain parts of IL-1 signaling. IL$1 \mathrm{Ra}$ is known to interact with all three IL-1RI receptor domains, whereas the Ilantide sequence motif includes only two residues from the binding site that is involved in the interaction with the Ig3 domain (see Figure 1B). Signaling via IL-1RI occurs only if the ligand-bound receptor associates with the IL-1RAcP protein. Two loops in IL-1Ra ( $\beta 4-\beta 5$ and $\beta 11-\beta 12)$ are determinants of the antagonism of IL-1Ra that prohibit ligand-bound IL-1RI 


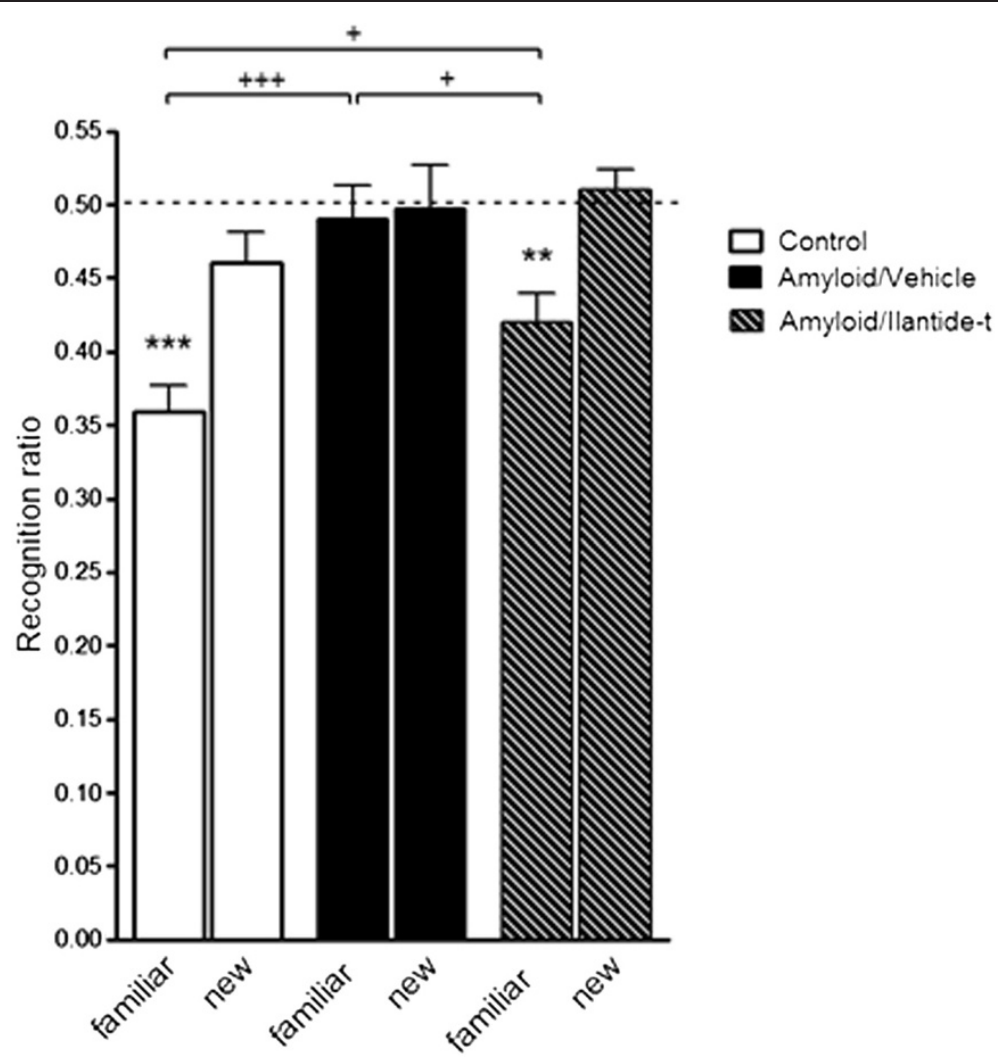

Figure 13 Ilantide reduces social memory deficits induced by amyloid- $\beta$. Ilantide-t (10 mg/kg; $n=12)$ or vehicle (saline, $1 \mathrm{ml} / \mathrm{kg} ; n=13)$ was subcutaneously injected on days postimmunization (dpi) 7, 9, 11, 13, 15, 17 and 19 after intracerebroventricular administration of aggregated $A \beta_{25-35}(15 \mu \mathrm{g})$. The control group consisted of 11 rats. The social recognition test was performed on dpi 20 . Social memory was estimated as the recognition ratio (RR). $R R_{\text {familiar }}$ was calculated as $T_{2} /\left(T_{1}+T_{2}\right) \cdot T_{1}$ and $T_{2}$ are the times spent investigating the same juvenile animal during the first and second trials, respectively. RR new was calculated as $T_{3} /\left(T_{1}+T_{3}\right) . T_{1}$ and $T_{3}$ are the times spent investigating the different juvenile animals during the first and third trials, respectively. An RR value significantly less than the theoretical value of 0.5 obtained by one-sample $t$-test was taken as an indication of the presence of social memory. ${ }^{* *} P<0.01$ and ${ }^{* * *} P<0.001$ by one-sample $t$-test compared with theoretical value of $0.5{ }^{+} P<0.05$ and ${ }^{+++} P<0.001$ by one-way analysis of variance followed by the Newman-Keuls post hoc test.

to recruit Il-1RAcP [40]. The Ilantide motif is far from these two loops, and the actual mechanism of the Ilantideinduced inhibition of IL-1 signaling might be somewhat different from that of Ana. From the pharmaceutical perspective, the chemically produced Ilantide peptide has a number of advantages over Ana (which belong to recombinant biologics), such as better penetration through the $\mathrm{BBB}$, better stability and less batch-to-batch variations.

Rheumatoid arthritis is triggered and maintained by cascades of inflammatory mediators. The current treatments for RA include neutralizing antibodies and antagonists of mediators of inflammation, particularly IL-1 and TNF- $\alpha$. We observed a positive effect of Ilantide in the CIA model that resembled several aspects of rheumatoid arthritis [41] when treatment began in the preclinical stage that corresponds to the first elevation of IL-1 levels in the blood. This result suggests that the blockade of IL-1 signaling with Ilantide may be an effective treatment for rheumatoid arthritis patients.
IL-1 receptors are well-known to be expressed in the brain $[42,43]$, and IL-1 is a key mediator of neuroinflammation. IL-1 $\beta$ is synthesized and released by microglia and astrocytes and regulates IL-1RI expression in neurons and astrocytes [44]. The neuron-specific effects of IL-1 $\beta$ were recently shown to be mediated by a novel isoform of IL-1RAcP-IL-1RAcPb, which results in the activation of $\mathrm{p} 38 \mathrm{MAPK}$, but not NF- $\mathrm{B}$, in hippocampal neurons [45]. However, the role of neuronal p38MAPK signaling is poorly understood [46]. We found that both Ilantide and recombinant IL-1Ra induced neuritogenesis and promoted the survival of primary neurons. The neuronal cultures used in our experiments did not contain microglial cells [47] and included less than 5\% astrocytes, which could be a source of IL-1 that affects the ability of neurons to differentiate and survive. Ilantide and IL-1Ra likely inhibited the effect of traces of IL-1 on IL-1RI, thereby triggering neuritogenesis and survival mechanisms. 
Intraperitoneal injections of LPS have been shown to induce IL-1 production in peripheral activated monocytes and macrophages, as well as in the brain (that is, the hypothalamus and hippocampus) [48]. IL-1 overproduction induces anorexia and depression, causing body weight loss and a reduction of social activity in rodents. One injection of Ilantide significantly ameliorated these effects of LPS, a potent inducer of IL-1 production. This peptide effect was accompanied by an increase in the plasma levels of the anti-inflammatory cytokine IL-10 in LPS-treated animals. We have shown in the present study that Ilantide crossed the BBB, which explains the protective effects of Ilantide on neuroinflammation. The ratio between Ilantide concentration in plasma and its concentration in CSF was 55, which is in good agreement with our previous results obtained for other peptides, the peptide derived from fibroblast growth factor receptor (plasma/CSF ratio $=10$ ) [49] and the peptide derived from the NCAM (plasma/CSF ratio $=40$ ) [50]. Reasonable BBB penetration of the peptide can also explain the cerebroprotective effect of Ilantide in the model of AD. IL-1 contributes to neuroinflammation during the progression of $\mathrm{AD}$. Intracerebroventricular administration of aggregated $A \beta_{25-35}$ induces neuroinflammation, which is manifested by the activation of microglia and astrocytes, neuronal damage and cognitive impairments [51] and overproduction of IL-1 in activated microglia [52]. Our in vitro data show that Ilantide promoted neural survival and neuritogenesis, which is an essential component of neuroplasticity and can explain the mnemotropic effect of Ilantide in the $\mathrm{AD}$ model.

EAE is often used as a model of multiple sclerosis in humans. The activation of endogenous IL-1 is involved in the progression of EAE, and IL-1Ra can reduce the clinical signs of the disease [53,54]. Comparisons of the beneficial effects of IL-1Ra and Ilantide showed that a more profound effect of IL-1Ra was achieved by a $26 \times$ higher total dose per kilogram compared with Ilantide in the present study [54]. Others have shown that the same dose [55] or a lower dose [56] of IL-1Ra has no significant effect on clinical scores.

In conclusion, we have identified a novel 10-amino acid peptide antagonist of IL-1, Ilantide, that binds to IL-1RI and inhibits the IL-1-induced activation of NF- $\mathrm{kB}$ and secretion of TNF- $\alpha$ by macrophages. The peptide protected pancreatic islets from IL-1 $\beta$-induced apoptosis and reduced inflammation in CIA. The Ilantide peptide penetrated the $\mathrm{BBB}$, diminished the deficit in social activity and memory in LPS- and amyloid-induced neuroinflammation and delayed the development of EAE in rats. We propose that this novel IL-1 antagonist can be used as an alternative to other IL-1 blockers to inhibit a variety of inflammatory conditions.

\section{Abbreviations}

AD: Alzheimer's disease; BBB: Blood-brain barrier; CIA: Collagen-induced arthritis; CSF: Cerebrospinal fluid; EAE: Experimental autoimmune encephalomyelitis; IFN: Interferon; IL: Interleukin; IL-1RAcP: Interleukin 1 receptor accessory protein; IL-1RI: Interleukin 1 receptor I; LPS: Lipopolysaccharide; MAPK: Mitogen-activated protein kinase; NF-kB: Nuclear factor KB; RA: Rheumatoid arthritis; SEAP: Secreted embryonic alkaline phosphatase; STAT: Signal transducer and activator of transcription; TNF: Tumor necrosis factor.

\section{Competing interests}

EB and VB are shareholders in Phlogo ApS (Denmark), which owns a patent on the llantide peptide. This does not alter the authors' adherence to all Journal of Neuroinflammation policies on sharing data and materials.

\section{Authors' contributions}

BK participated in the design of in vivo studies; carried out in vivo experiments on LPS, CIA and AD; and drafted the manuscript. SL carried out the binding and TNF secretion studies. IK carried out the pharmacokinetics study. OD and SP participated in study design and carried out the EAE and ELISA studies. PSW participated in study design and the coordination of EAE study and helped to draft the manuscript. LKK carried out the pancreatic islets study and helped to draft the manuscript. MSD, ML and DPC participated in the pancreatic islets study and statistical analysis. TMP designed and coordinated the pancreatic islets study and participated in drafting the manuscript. EB participated in designing the in vitro and in vivo studies and helped to draft the manuscript. VB designed and coordinated the whole project and, together with BK, drafted the manuscript. All authors read and approved the final manuscript.

\section{Acknowledgements}

This work was financially supported by grants from the Lundbeck Foundation, the Danish Rheumatism Association (University of Copenhagen), the Danish Multiple Sclerosis Society, the European Foundation for the Study of Diabetes, the Juvenile Research Foundation International and the Novo Nordisk Foundation.

\section{Author details}

'Laboratory of Neural Plasticity, Department of Neuroscience and Pharmacology, University of Copenhagen, Blegdamsvej 3, DK-2200 Copenhagen, Denmark. ${ }^{2}$ Section of Endocrinological Research, Department of Biomedical Sciences, University of Copenhagen, Blegdamsvej 3, DK-2200 Copenhagen, Denmark. ${ }^{3}$ Department of Molecular Medicine and Surgery, Karolinska Institute, Solna (L1:00), SE-171 77 Stockholm, Sweden.

Received: 26 July 2013 Accepted: 20 January 2014

Published: 3 February 2014

\section{References}

1. Dinarello CA, Simon A, van der Meer JW: Treating inflammation by blocking interleukin-1 in a broad spectrum of diseases. Nat Rev Drug Discov 2012, 11:633-652.

2. Sims JE, Gayle MA, Slack JL, Alderson MR, Bird TA, Giri JG, Colotta F, Re F, Mantovani A, Shanebeck K, Grabstein KH, Dower SK: Interleukin 1 signaling occurs exclusively via the type I receptor. Proc Natl Acad Sci USA 1993, 90:6155-6159.

3. Hannum CH, Wilcox CJ, Arend WP, Joslin FG, Dripps DJ, Heimdal PL, Armes $L G$, Sommer A, Eisenberg SP, Thompson RC: Interleukin-1 receptor antagonist activity of a human interleukin-1 inhibitor. Nature 1990, 343:336-340.

4. Dinarello CA: Biologic basis for interleukin-1 in disease. Blood 1996, 87:2095-2147.

5. Cohen SB, Moreland LW, Cush JJ, Greenwald MW, Block S, Shergy WJ, Hanrahan PS, Kraishi MM, Patel A, Sun G, Bear MB, 990145 Study Group: A multicentre, double blind, randomised, placebo controlled trial of anakinra (Kineret), a recombinant interleukin 1 receptor antagonist, in patients with rheumatoid arthritis treated with background methotrexate. Ann Rheum Dis 2004, 63:1062-1068.

6. Dinarello CA: A clinical perspective of IL-1 $\beta$ as the gatekeeper of inflammation. Eur J Immunol 2011, 41:1203-1217.

7. Skinner RA, Gibson RM, Rothwell NJ, Pinteaux E, Penny J: Transport of interleukin-1 across cerebromicrovascular endothelial cells. Br J Pharmacol 2009, 156:1115-1123. 
8. Dantzer R, Bluthé RM, Gheusi G, Cremona S, Layé S, Parnet P, Kelley KW: Molecular basis of sickness behavior. Ann NY Acad Sci 1998, 856:132-138.

9. Rønn LCB, Olsen M, Østergaard S, Kiselyov V, Berezin V, Mortensen MT, Lerche $\mathrm{MH}$, Jensen $\mathrm{PH}$, Soroka V, Saffell JL, Doherty P, Poulsen FM, Bock E, Holm A: Identification of a neuritogenic ligand of the neural cell adhesion molecule using a combinatorial library of synthetic peptides. Nat Biotechnol 1999, 17:1000-1005.

10. Schousboe A, Frandsen A, Drejer J: Evidence for evoked release of adenosine and glutamate from cultured cerebellar granule cells. Neurochem Res 1989, 14:871-875.

11. Brunstedt J: Rapid isolation of functionally intact pancreatic islets from mice and rats by Percoll gradient centrifugation. Diabetes Metab 1980, 6:87-89.

12. Humphreys DT, Wilson MR: Modes of L929 cell death induced by TNF-a and other cytotoxic agents. Cytokine 1999, 11:773-782.

13. Lundh M, Christensen DP, Rasmussen DN, Mascagni P, Dinarello CA, Billestrup N, Grunnet LG, Mandrup-Poulsen T: Lysine deacetylases are produced in pancreatic $\beta$ cells and are differentially regulated by proinflammatory cytokines. Diabetologica 2010, 53:2569-2578.

14. Køhler LB, Soroka V, Korshunova I, Berezin V, Borck E: A peptide derived from a trans-homophilic binding site in neural cell adhesion molecule induces neurite outgrowth and neuronal survival. J Neurosci Res 2010, $88: 2165-2176$

15. Pankratova S, Kiryushko D, Sonn K, Soroka V, Køhler LB, Rathje M, Gu B, Gotfryd K, Clausen O, Zharkovsky A, Bock E, Berezin V: Neuroprotective properties of a novel, non-haematopoietic agonist of the erythropoietin receptor. Brain 2010, 133:2281-2294.

16. Hudson LC, Hughes CS, Bold-Fletcher NO, Vaden SL: Cerebrospinal fluid collection in rats: modification of a previous technique. Lab Anim Sci 1994, 44:358-361.

17. Smith CP, Bores GM, Petko W, Li M, Selk DE, Rush DK, Camacho F, Winslow JT, Fishkin R, Cunningham DM, Brooks KM, Roehr J, Hartman HB, Davis L, Vargas HM: Pharmacological activity and safety profile of P10358, a novel, orally active acetylcholinesterase inhibitor for Alzheimer's disease. J Pharmacol Exp Ther 1997, 280:710-720.

18. van Kampen M, Selbach K, Schneider R, Schiegel E, Boess F, Schreiber R: AR-R 17779 improves social recognition in rats by activation of nicotinic $a_{7}$ receptors. Psychopharmacology (Berl) 2004, 172:375-383.

19. Schreuder H, Tardif C, Trump-Kallmeyer S, Soffientini A, Sarubbi E, Akeson A, Bowlin T, Yanofsky S, Barrett RW: A new cytokine-receptor binding mode revealed by the crystal structure of the IL-1 receptor with an antagonist. Nature 1997, 386:194-200.

20. Brown KD, Claudio E, Siebenlist U: The roles of the classical and alternative nuclear factor-kB pathways: potential implications for autoimmunity and rheumatoid arthritis. Arthritis Res Ther 2008, 10:212.

21. Dinarello CA: Proinflammatory cytokines. Chest 2000, 118:503-508.

22. Gabay C: Cytokine inhibitors in the treatment of rheumatoid arthritis. Expert Opin Biol Ther 2002, 2:135-149.

23. McColl BW, Rothwell NJ, Allan SM: Systemic inflammatory stimulus potentiates the acute phase and CXC chemokine responses to experimental stroke and exacerbates brain damage via interleukin-1- and neutrophil-dependent mechanisms. J Neurosci 2007, 27:4403-4412.

24. Vezzani A, Moneta D, Conti M, Richichi C, Ravizza T, De Luigi A, De Simoni MG, Sperk G, Andell-Jonsson S, Lundkvist J, Iverfeldt K, Bartfai T: Powerful anticonvulsant action of IL-1 receptor antagonist on intracerebral injection and astrocytic overexpression in mice. Proc Natl Acad Sci USA 2000, 97:11534-11539.

25. Tehranian R, Andell-Jonsson S, Beni SM, Yatsiv I, Shohami E, Bartfai T, Lundkvist J, Iverfeldt K: Improved recovery and delayed cytokine induction after closed head injury in mice with central overexpression of the secreted isoform of the interleukin-1 receptor antagonist. J Neurotrauma 2002, 19:939-951.

26. Andoh T, Kishi H, Motoki K, Nakanishi K, Kuraishi Y, Muraguchi A: Protective effect of IL-18 on kainate- and IL-1 $\beta$-induced cerebellar ataxia in mice. J Immunol 2008, 180:2322-2328.

27. Gardoni F, Boraso M, Zianni E, Corsini E, Galli CL, Cattabeni F, Marinovich M, Di Luca M, Viviani B: Distribution of interleukin-1 receptor complex at the synaptic membrane driven by interleukin- $1 \beta$ and NMDA stimulation. J Neuroinflammation 2011, 8:14.

28. Davis CN, Tabarean I, Gaidarova S, Behrens MM, Bartfai T: IL-1 $\beta$ induces a MyD88-dependent and ceramide-mediated activation of Src in anterior hypothalamic neurons. J Neurochem 2006, 98:1379-1389.
29. Mandrup-Poulsen T, Pickersgill L, Donath MY: Blockade of interleukin 1 in type 1 diabetes mellitus. Nat Rev Endocrinol 2010, 6:158-166.

30. Zumsteg U, Reimers JI, Pociot F, Mørch L, Helqvist S, Brendel M, Alejandro R, Mandrup-Poulsen T, Dinarello CA, Nerup J: Differential interleukin-1 receptor antagonism on pancreatic $\beta$ and a cells: studies in rodent and human islets and in normal rats. Diabetologica 1993, 36:759-766.

31. Kay J, Upchurch KS: ACR/EULAR 2010 rheumatoid arthritis classification criteria. Rheumatology (Oxford) 2012, 51(Suppl 6):vi5-vi9.

32. Stolina M, Bolon B, Dwyer D, Middleton S, Duryea D, Kostenuik PJ, Feige U, Zack DJ: The evolving systemic and local biomarker milieu at different stages of disease progression in rat collagen-induced arthritis. Biomarkers 2008, 13:692-712.

33. Arend WP: The balance between IL-1 and IL-1Ra in disease. Cytokine Growth Factor Rev 2002, 13:323-340.

34. Allan SM, Tyrrell PJ, Rothwell NJ: Interleukin-1 and neuronal injury. Nat Rev Immunol 2005, 5:629-640.

35. Sims JE, Smith DE: The IL-1 family: regulators of immunity. Nat Rev Immunol 2010, 10:89-102.

36. Bao J, Yue T, Liu W, Zhang Q, Zhou L, Xu HJ, Dai SM: Secondary failure to treatment with recombinant human IL-1 receptor antagonist in Chinese patients with rheumatoid arthritis. Clin Rheumatol 2011, 30:697-701.

37. Kaiser C, Knight A, Nordström D, Pettersson T, Fransson J, Florin-Robertsson E, Pilström B: Injection-site reactions upon Kineret (anakinra) administration: experiences and explanations. Rheumatol Int 2012, 32:295-299.

38. Jonville-Bera AP, Guilmot JL, Aspe G, Autret-Leca E, Magnant J: Is exogenous administration of IL-1ra (anakinra) likely to induce severe depression? Eur J Clin Pharmacol 2011, 67:213-214.

39. Larsen CM, Faulenbach M, Vaag A, Vølund A, Ehses JA, Seifert B, MandrupPoulsen T, Donath MY: Interleukin-1-receptor antagonist in type 2 diabetes mellitus. N Engl J Med 2007, 356:1517-1526.

40. Wang D, Zhang S, Li L, Liu X, Mei K, Wang X: Structural insights into the assembly and activation of IL-1 $\beta$ with its receptors. Nat Immunol 2010, 11:905-911.

41. Hegen M, Keith JC Jr, Collins M, Nickerson-Nutter CL: Utility of animal models for identification of potential therapeutics for rheumatoid arthritis. Ann Rheum Dis 2008, 67:1505-1515.

42. Takao T, Tracey DE, Mitchell WM, De Souza EB: Interleukin-1 receptors in mouse brain: characterization and neuronal localization. Endocrinology 1990, 127:3070-3078.

43. Yabuuchi K, Minami M, Katsumata S, Satoh M: Localization of type I interleukin-1 receptor mRNA in the rat brain. Brain Res Mol Brain Res 1994, 27:27-36.

44. Friedman WJ: Cytokines regulate expression of the type 1 interleukin-1 receptor in rat hippocampal neurons and glia. Exp Neurol 2001, 168:23-31.

45. Huang Y, Smith DE, Ibáñez-Sandoval O, Sims JE, Friedman WJ: Neuronspecific effects of interleukin- $1 \beta$ are mediated by a novel isoform of the IL-1 receptor accessory protein. J Neurosci 2011, 31:18048-18059.

46. Takeda K, Ichijo H: Neuronal p38 MAPK signalling: an emerging regulator of cell fate and function in the nervous system. Genes Cells 2002, 7:1099-1111.

47. Pankratova S, Gu B, Kiryushko D, Korshunova I, Køhler LB, Rathje M, Bock E, Berezin V: A new agonist of the erythropoietin receptor, Epobis, induces neurite outgrowth and promotes neuronal survival. J Neurochem 2012, 121:915-923.

48. Layé S, Parnet P, Goujon E, Dantzer R: Peripheral administration of lipopolysaccharide induces the expression of cytokine transcripts in the brain and pituitary of mice. Brain Res Mol Brain Res 1994, 27:157-162.

49. Enevoldsen MN, Kochoyan A, Jurgenson M, Jaako K, Dmytriyeva O, Walmod PS, Nielsen JD, Nielsen J, Li S, Korshunova I, Klementiev B, Novikova T, Zharkovsky A, Berezin $V$, Bock E: Neuroprotective and memory enhancing properties of a dual agonist of the FGF receptor and NCAM. Neurobiol Dis 2012, 48:533-545.

50. Klementiev B, Novikova T, Korshunova I, Berezin V, Bock E: The NCAMderived $\mathrm{P} 2$ peptide facilitates recovery of cognitive and motor function and ameliorates neuropathology following traumatic brain injury. Eur J Neurosci 2008, 27:2885-2896.

51. Klementiev B, Novikova T, Novitskaya V, Walmod PS, Dmytriyeva O, Pakkenberg B, Berezin V, Bock E: A neural cell adhesion molecule-derived peptide reduces neuropathological signs and cognitive impairment induced by $A \beta_{25-35}$. Neuroscience 2007, 145:209-224. 
52. Meda L, Baron P, Prat E, Scarpini E, Scarlato G, Cassatella MA, Rossi F: Proinflammatory profile of cytokine production by human monocytes and murine microglia stimulated with $\beta$-amyloid $25-35$. J Neuroimmunol 1999, 93:45-52.

53. Schiffenbauer J, Streit WJ, Butfiloski E, LaBow M, Edwards C 3rd, Moldawer $\mathrm{LL}$ : The induction of EAE is only partially dependent on TNF receptor signaling but requires the IL-1 type I receptor. Clin Immunol 2000, 95:117-123.

54. Martin D, Near SL: Protective effect of the interleukin-1 receptor antagonist (IL-1 ra) on experimental allergic encephalomyelitis in rats. J Neuroimmunol 1995, 61:241-245.

55. Pollak Y, Ovadia H, Orion E, Yirmiya R: The EAE-associated behavioral syndrome: II. Modulation by anti-inflammatory treatments. J Neuroimmunol 2003, 137:100-108.

56. Badovinac V, Mostarica-Stojković M, Dinarello CA, Stošić-Grujičić S: Interleukin-1 receptor antagonist suppresses experimental autoimmune encephalomyelitis (EAE) in rats by influencing the activation and proliferation of encephalitogenic cells. J Neuroimmunol 1998, 85:87-95.

doi:10.1186/1742-2094-11-27

Cite this article as: Klementiev et al:: Anti-inflammatory properties of a novel peptide interleukin 1 receptor antagonist. Journal of Neuroinflammation 2014 11:27.

\section{Submit your next manuscript to BioMed Central and take full advantage of:}

- Convenient online submission

- Thorough peer review

- No space constraints or color figure charges

- Immediate publication on acceptance

- Inclusion in PubMed, CAS, Scopus and Google Scholar

- Research which is freely available for redistribution 